\title{
PORQUE O NORDESTE PRODUZ SAL MARINHO? Estudo analógico do potencial do clima
}

\author{
WHY DOES THE NORTHEAST PRODUCE MARINE SALT? Analogical study of \\ climate potential
}

Marco Túlio Mendonça Diniz Docente do Mestrado Profissional em Ensino de Geografia e do Departamento de Geografia do CERES/UFRN tuliogeografia@gmail.com

Fábio Perdigão Vasconcelos Docente do Programa de Pós-Graduação em Geografia da UECE fabioperdigao@gmail.com

\begin{abstract}
Resumo:
A região conhecida como Costa Semiárida Brasileira (CSB) - trecho que se estende do Golfo do Maranhão ao Cabo do Calcanhar (RN) - produz cerca de $98 \%$ do sal marinho do país, o objetivo do trabalho foi investigar quais os parâmetros meteorológico-climático condicionam o maior potencial para a produção de sal marinho na Costa Semiárida Brasileira, especialmente numa região do estado do Rio Grande do Norte que produz cerca de $95 \%$ do total nacional. Analisou-se de todos os parâmetros do clima em todas as estações com informações disponíveis localizadas na Costa Semiárida Brasileira onde predominam os climas semiáridos e semiúmidos, nestes subtipos de clima se produz cerca de $98 \%$ do sal marinho brasileiro, além disso foi delimitada a duração da estação chuvosa, utilizando a metodologia de Gaussen e Bagnouls. Após a análise dos sistemas atmosféricos atuantes e das normais do clima conclui-se que, do ponto de vista climático, os dois trechos côncavos da CSB são os de maior potencial para a produção de sal marinho, pois neles é menor a taxa de precipitação e a umidade relativa do ar, sendo maior a velocidade dos ventos e a temperatura, o que concorre para serem maiores também as taxas de evaporação da água. A situação é tanto mais favorável na Costa Branca, especialmente no Rio Grande do Norte, e de forma ainda mais marcante na região de Macau, onde todos os principais indicadores apontam para um maior potencial para a produção de sal marinho dessa área.
\end{abstract}

Palavras-chave: Geografia Física do Nordeste; Climatologia Geográfica; Costa Semiárida do Brasil, Salinas.

\begin{abstract}
:
The region known as the Brazilian Semiarid Cost (BSC) - portions extending from the Gulf of Maranhão to Cabo do Calcanhar (RN) - produces about $98 \%$ of sea salt in the country, the aim of this study was to investigate which weather-climatic parameters condition the most potential for sea salt production in Brazilian Semiarid Cost, especially in Rio Grande do Norte state, region that produces about $95 \%$ of the national salt. It analyzed all the climate parameters in all seasons with localized information available in the area dominated by semiarid and semi-wet climates, these climate subtypes produces about $98 \%$ of the Brazilian sea salt, also the duration of the rainy season was defined using the methodology of Gaussen and Bagnouls. After analyzing the active weather systems and the normal climate is concluded that, from a climate perspective, the two concave portions of the BSC are the most potential for the production of sea salt, there are lower precipitation rate and the relative humidity, with a higher wind speed and temperature, which
\end{abstract}


contributes to that they are also the evaporation rates of water. The situation is much more favorable in White Coast, especially in Rio Grande do Norte, and even more markedly in the Macau region, where all the main indicators point to a greater potential for the production of sea salt in that area.

Keywords: Physical Geography of Northeast; Geographic Climatology; Semiarid Coast of Brazil, Salt Works.

\section{INTRODUÇÃO}

O sal é um dos principais insumos para indústria química, sem ele a indústria química (incluindo a indústria de petróleo) não existiria como é conhecida, no Brasil o sal marinho responde pela maior parte $(5,9 \mathrm{Mt})$ da produção total de sal (7,2 Mt).

Vários elementos e fatores do clima podem ser considerados como condicionantes para a produção de sal marinho, dentre os elementos climáticos destacam-se a temperatura, umidade do ar, precipitação, insolação e vento. Esses elementos são controlados por fatores climáticos como latitude, altitude, maritimidade, continentalidade, massas de ar e rugosidade do relevo. De modo geral, quanto menores as precipitações pluviométricas, mais velozes forem os ventos, menor for a umidade relativa do ar e maiores forem as temperaturas, mais rapidamente os tanques evaporarão as águas salinas, o que aumentará a produtividade da propriedade que se dedique a produzir sal marinho.

O objetivo do trabalho foi investigar quais os parâmetros meteorológico-climático condicionam o maior potencial para a produção de sal marinho na Costa Semiárida Brasileira. Os demais parâmetros naturais não foram considerados nesta pesquisa, eles foram apresentados no capítulo quarto da obra de Diniz et al. (2016).

\section{MATERIAIS E MÉTODOS}

Foram analisados alguns parâmetros climatológicos com base na publicação Normais Climatológicas do Brasil 1961-1990 (INMET, 2009). As normais são descritas, explicadas e analisadas levando em consideração os fatores controladores do clima, dentre os quais os mecanismos dinâmicos que regem o clima da área em estudo. De forma complementar, foram utilizados dados de pluviometria da SUDENE (1990) em alguns pontos onde há ausência de dados do INMET.

Analisou-se informações disponíveis em todas as estações meteorológicas localizadas num trecho que se estende do Golfo do Maranhão ao Cabo do Calcanhar (RN), trecho denominado por Diniz e Oliveira (2016) de Costa Semiárida Brasileira (CSB) onde predominam os subtipos de 
clima semiárido e semiúmido, nestes subtipos de clima se produz cerca de $98 \%$ do sal marinho brasileiro. Em alguns casos os dados da estação de Natal, capital do Estado do Rio Grande do Norte, foram analisados para mostrar as diferenças da transição do clima semiárido para o clima úmido do Nordeste Oriental, e de São Luís e Turiaçu no Maranhão para que fosse compreendida a transição para o clima Equatorial. A localização geográfica das estações analisadas está na Tabela 1. As informações climatológicas da estação de Cabo Frio no Estado do Rio de Janeiro (única área a produzir sal fora da CSB) foram incluídas na tabela 2, a título de comparação com os dados da Região Nordeste.

Tabela 1: Localização das estações meteorológicas analisadas.

\begin{tabular}{cccc}
\hline ESTAÇÕES & LATITUDE & LONGITUDE & ALTITUDE (m) \\
\hline Turiaçu - MA & $01^{\circ} 34^{\prime} \mathrm{S}$ & $45^{\circ} 22^{\prime} \mathrm{W}$ & 44,1 \\
São Luís - MA & $02^{\circ} 32^{\prime} \mathrm{S}$ & $44^{\circ} 13^{\prime} \mathrm{W}$ & 50,9 \\
\hline Parnaíba - PI & $03^{\circ} 05^{\prime} \mathrm{S}$ & $41^{\circ} 46^{\prime} \mathrm{W}$ & 79,5 \\
Acaraú - CE & $02^{\circ} 53^{\prime} \mathrm{S}$ & $40^{\circ} 08^{\prime} \mathrm{W}$ & 16,5 \\
Fortaleza - CE & $03^{\circ} 45^{\prime} \mathrm{S}$ & $38^{\circ} 33^{\prime} \mathrm{W}$ & 26,5 \\
Aracati - CE & $04^{\circ} 34^{\prime} \mathrm{S}$ & $37^{\circ} 46^{\prime} \mathrm{W}$ & 13,0 \\
Jaguaruana - CE & $04^{\circ} 47^{\prime} \mathrm{S}$ & $37^{\circ} 46^{\prime} \mathrm{W}$ & 11,7 \\
Mossoró - RN & $05^{\circ} 12^{\prime} \mathrm{S}$ & $37^{\circ} 18^{\prime} \mathrm{W}$ & 38,0 \\
Macau - RN & $05^{\circ} 07^{\prime} \mathrm{S}$ & $36^{\circ} 46^{\prime} \mathrm{W}$ & 3,4 \\
Natal - RN & $05^{\circ} 55^{\prime} \mathrm{S}$ & $35^{\circ} 12^{\prime} \mathrm{W}$ & 48,6 \\
Cabo Frio (Álcalis) - RJ & $2^{\circ} 59^{\prime} \mathrm{S}$ & $42^{\circ} 02^{\prime} \mathrm{W}$ & 7,0 \\
\hline
\end{tabular}

Fonte: Normais Climatológicas do Brasil 1961-1990

O litoral em questão tem dois trechos côncavos e um convexo em relação ao Atlântico, as estações de Fortaleza e Macau estão em posições quase centrais da Costa Branca (Trecho Convexo, entre o Cabo do Calcanhar e Icapuí) em relação ao oceano, e da Costa das Dunas (Trecho Côncavo, entre Icapuí e a foz do Acaraú), respectivamente. Para a Costa dos Deltas (Trecho Côncavo, entre o Golfo do Maranhão e a foz do Acaraú), foram utilizados os dados disponíveis da estação climatológica de Parnaíba no Estado do Piauí (Figura 1).

Para a delimitação de meses secos e chuvosos utilizou-se o critério adotado por Gaussen e Bagnouls (1953), que consideram mês seco aquele cujo total das precipitações em milímetros é igual ou inferior ao dobro da temperatura em graus celsius $(\mathrm{P} \leq 2 \mathrm{~T})$. Para a determinação de subseca adotou-se a fórmula $2 \mathrm{~T}<\mathrm{P} \leq 3 \mathrm{~T}$ de Walter e Lieth (1960). Calculou-se ainda a quantidade de anos chuvosos, de anos normais e de anos secos em um período de trinta anos (1961-1990) nos postos pluviométricos de Jaguaruana e Areia Branca, únicos que dispunham de dados para o período da normal. Para esta caracterização foram considerados os seguintes parâmetros, para $\mathrm{P}=$ precipitação e $\mathrm{M}$ = média das precipitações do período, sendo: ano chuvoso - precipitação pelo menos $15 \%$ superior à média $(\mathrm{P}>1,15 \mathrm{M})$; ano normal - até $15 \%$ de precipitação a mais ou a menos 
que a média $(0,85 \mathrm{M} \leq \mathrm{P} \leq 1,15 \mathrm{M})$; e ano seco - precipitação pelo menos $15 \%$ inferior à média $(\mathrm{P}<$ $0,85 \mathrm{M})$.

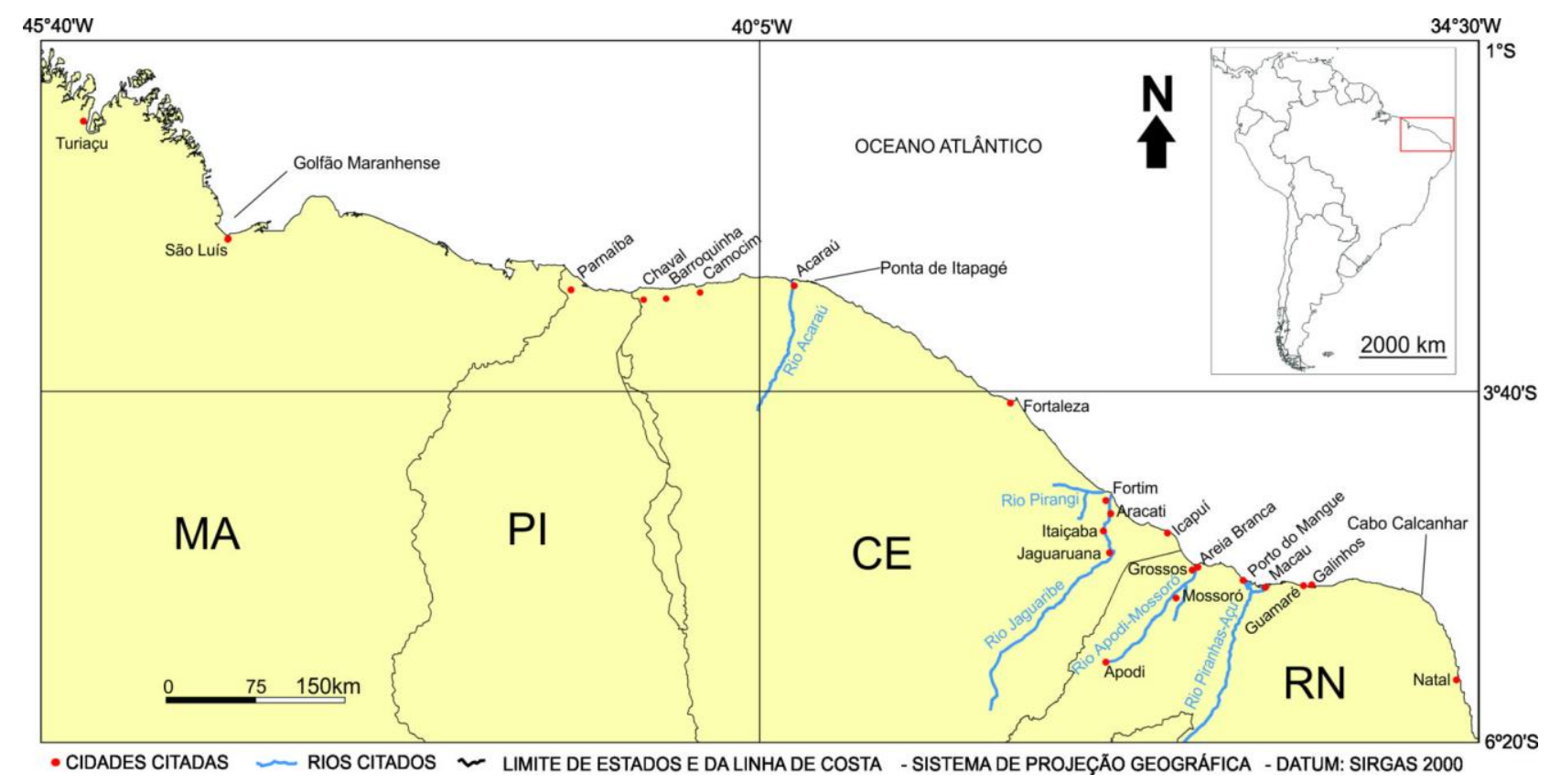

Figura 1: Localização da Costa Semiárida Brasileira e de outros locais mencionados no texto.

\section{RESULTADOS E DISCUSSÃO}

Atualmente no Brasil existe apenas uma área localizada fora da CSB que produz sal marinho localizada na Lagoa de Araruama (RJ), a análise dos resultados se inicia justificando o menor potencial para produção de sal marinho nesta área, onde a constância do clima Tropical do Brasil Central sem estação seca (MENDONÇA; DANNI-OLIVEIRA, 2007) de Cabo Frio contrasta com a semiaridez dos estados nordestinos. Em Cabo Frio, o déficit entre precipitação e evaporação anuais é de apenas 68,9 mm/ano, enquanto que em Macau esse mesmo déficit passa dos $2000 \mathrm{~mm} / \mathrm{ano}$ (Tabela 1). As salinas do Rio de Janeiro também não podem colher camadas de sal maiores que 2 ou $3 \mathrm{~cm}$ por conta de seu clima constante, que tem apenas um mês seco, em média, durante o ano (agosto), uma vez que suas chuvas mais constantes diluem o sal concentrado nos evaporadores. Em Jaguaruana (CE) tem-se em média 7 meses secos durante o ano, o número chega a 8 em Macau, essa extensa estação sem chuvas faz com que os produtores do Rio Grande do Norte possam retirar 3 safras com camadas de mais de $10 \mathrm{~cm}$ de sal marinho precipitado nos tanques. Os números apresentados contribuem para acreditar a tese de que as condições naturais mais favoráveis nas salinas do Nordeste em relação ao Rio de Janeiro são fatores determinantes para uma ampla 
vantagem produtiva das salinas da CSB, nas próximas linhas são apresentados os resultados da investigação nos estados produtores desta área: Ceará (CE), Piaú (PI) e Rio Grande do Norte (RN).

Tabela 2: Precipitação média (1961-1990) compensada (mm), evaporação média compensada (mm), déficit entre precipitação e evaporação $(\mathrm{mm})$; e quantidade de meses secos $(\mathrm{P} \leq 2 \mathrm{~T}$, onde $\mathrm{P}=$ Precipitação e $\mathrm{T}=\mathrm{Temperatura})$, em estações selecionadas nas principais regiões produtoras de sal marinho no Ceará, Rio Grande do Norte e Rio de Janeiro.

\begin{tabular}{lcccc}
\hline ESTAÇÕES & P $(\mathrm{mm})$ & $\mathrm{E}(\mathrm{mm})$ & $\mathrm{P}-\mathrm{E} .(\mathrm{mm})$ & $\mathrm{P} \leq 2 \mathrm{~T}$ \\
\hline Acaraú - CE & 1545,2 & 2114,8 & $-569,6$ & 6 \\
Jaguaruana - CE & 862,0 & 2007,2 & $-1145,2$ & 7 \\
Mossoró-RN & 787,9 & 1989,5 & $-1201,6$ & 7 \\
Macau - RN & 507,2 & 2591,4 & $-2084,2$ & 8 \\
Cabo Frio - RJ & 784,5 & 853,4 & $-68,9$ & 1
\end{tabular}

Fonte: Normais Climatológicas do Brasil 1961-1990.

\subsection{Do regime de chuvas}

Os mecanismos dinâmicos que produzem chuvas no Nordeste do Brasil (NEB) podem ser classificados em mecanismos de grande escala, mesoescala e microescala, sendo os primeiros responsáveis pela maior parte da precipitação observada (MOLION ; BERNARDO, 2002).

Dentre os mecanismos de grande escala, destacam-se a atuação da Zona de Convergência Intertropical (ZCIT) e dos sistemas frontais ou frentes frias. Perturbações ondulatórias no campo dos ventos Alísios (POA), complexos convectivos, vórtices ciclônicos de altos níveis (VCAN), brisas marinhas e terrestres fazem parte da mesoescala, enquanto que as circulações orográficas se constituem como exemplo de mecanismos de microescala.

Dentre os mecanismos de grande escala, o sistema atuante na área é a ZCIT, toda a CSB está sob influência da ZCIT, esta é responsável pela maior parte da precipitação registrada na área. Em seu trecho mais a sudeste, os eventos de precipitação dependem quase que exclusivamente desse sistema.

A confluência dos alísios de Nordeste e de Sudeste e a convergência de massas em baixos níveis favorecem o transporte de umidade e o aumento da atividade convectiva, em especial sobre o NEB.

Segundo Melo, Cavalcanti e Souza (2009, p.25) em relação ao Atlântico Equatorial a ZCIT migra sazonalmente de sua posição mais ao norte, próximo aos $14^{\circ} \mathrm{N}$ (agosto-setembro), para sua posição mais ao sul aproximadamente aos $2^{\circ} \mathrm{S}$ (março-abril). Os autores afirmam ainda que "em anos chuvosos, a ZCIT pode atingir até $5^{\circ} \mathrm{S}$, perto da costa nordestina", essas posições tratam do centro de atuação do sistema, em especial de sua banda principal, podendo ocorrer uma banda secundária no Hemisfério Sul (HS). 
Em anos em que não se forma a banda secundária da ZCIT no HS nas proximidades do Oceano Atlântico, o ano tende a ser mais seco no Litoral Piauiense (LP), no Litoral Cearense (LC) e no Litoral Setentrional Potiguar (LSP), em especial neste, o que se deve à sua posição mais austral.

Garcia (apud MELO; CAVALCANTI; SOUZA, 2009) destacou que a atuação preferencial da ZCIT se dá nas áreas tropicais do Hemisfério Norte (HN), devido às águas mais aquecidas nessas áreas. Além disso, as águas frias do leste do Oceano Pacífico e do Atlântico também contribuem para a posição da ZCIT no HN na maior parte do ano. No mês de abril, quando a ZCIT tem sua máxima atuação no HS, ela assume uma posição SW-NE, dado que as águas costeiras do Atlântico Oeste nas latitudes de atuação da ZCIT são mais aquecidas que na parte leste desse oceano, ficando sobre o Norte do Brasil e o NEB, a máxima atividade convectiva do sistema.

$\mathrm{Na}$ CSB, o mais comum é que o principal sistema responsável por precipitações na área atue com maior frequência e intensidade em posições setentrionais em relação ao paralelo de $3^{\circ} \mathrm{S}$. Dessa forma, os totais pluviométricos ocasionados pela ZCIT tendem a decrescer do Maranhão para o LSP, já que esse está quase que completamente posicionado ao sul do paralelo dos $5^{\circ} \mathrm{S}$ (apenas seu ponto mais ao norte está em torno dos $4^{\circ} 50$ 'S).

A posição SW-NE da ZCIT mesmo em anos chuvosos não favorece o LSP em termos de precipitação pluviométrica que tende a ser um pouco mais elevada no LC e no LP, isso ocorre dada a sua posição no extremo sudeste da CSB, que é atingida mais tardiamente pela atividade convectiva da ZCIT. Da mesma forma, o LSP é abandonado mais cedo pelo sistema que o LC e o LP, quando a ZCIT inicia seu retorno para o HN.

A CSB passa a ser atingida pela ZCIT no mês de janeiro, mas quase que exclusivamente no LP e no LC. O LSP é submetido aos sistemas convectivos de forma mais forte em abril, o que faz sua estação seca ser maior que a do trecho mais setentrional da CSB. Vale salientar, que mesmo no mês de abril, podemos perceber que os sistemas convectivos profundos ocorrem com maior frequência no LP e no LC do que no LSP. Em seu retorno ao HN a ZCIT ainda é responsável por fortes atividades convectivas na CSB, no mês de maio, o que ocorre de forma mais marcante nos trechos de menor latitude. O fato pode ser identificado nas médias acima de $250 \mathrm{~mm}$ em Fortaleza e Parnaíba e abaixo dos $110 \mathrm{~mm}$ em Mossoró e dos $80 \mathrm{~mm}$, em Macau, no mesmo mês de maio (Quadro 1). As precipitações que ocorrem, a partir de junho, praticamente não dependem mais do sistema em questão. Daí a diminuição drástica nas chuvas, especialmente no LSP, que deve suas precipitações pluviométricas quase que exclusivamente à ZCIT. 
Quadro 1 - Precipitação média acumulada mensal e anual ( $\mathrm{mm}$ ) em estações selecionadas.

\begin{tabular}{|l|l|l|l|l|l|l|l|l|l|l|l|l|l|}
\hline Estações & JAN & FEV & MAR & ABR & MAI & JUN & JUL & AGO & SET & OUT & NOV & DEZ & Ano \\
\hline Turiaçu - MA & 192,3 & 392,4 & 443,0 & 387,0 & 280,0 & 199,6 & 157,4 & 55,7 & 16,4 & 16,3 & 19,5 & 62,5 & 2222,0 \\
\hline São Luís - MA & 244,2 & 373,0 & 428,0 & 475,9 & 316,5 & 173,3 & 131,1 & 29,4 & 23,3 & 7,6 & 10,5 & 77,4 & 2290,0 \\
\hline Parnaíba - PI & 142,5 & 254,8 & 371,1 & 405,7 & 255,1 & 72,8 & 37,4 & 1,1 & 3,2 & 3,4 & 5,6 & 43,7 & 1596,4 \\
\hline Acaraú - CE & 152,3 & 207,2 & 434,9 & 397,8 & 194,5 & 68,3 & 42,4 & 6,0 & 3,6 & 3,6 & 4,1 & 30,6 & 1545,2 \\
\hline Fortaleza - CE & 119,1 & 204,6 & 323,1 & 356,1 & 255,6 & 141,8 & 94,7 & 21,8 & 22,7 & 13 & 11,8 & 44,1 & 1609,4 \\
\hline Jaguaruana - CE & 60,0 & 87,6 & 261,3 & 188,6 & 142,7 & 52,1 & 48,4 & 3,8 & 5,1 & 2,5 & 0,9 & 9,0 & 862,0 \\
\hline Mossoró-RN & 69,3 & 130,1 & 169,2 & 179,6 & 109,5 & 49,4 & 39,9 & 11,1 & 5,9 & 3,4 & 3,2 & 17,3 & 787,9 \\
\hline Macau - RN & 29,7 & 64,8 & 120,0 & 134,5 & 73,8 & 35,5 & 26,7 & 5,7 & 4,8 & 0,8 & 2,6 & 8,3 & 507,2 \\
\hline Natal - RN & 54,6 & 87,3 & 195,8 & 264,7 & 239,6 & 202,2 & 196,9 & 112,6 & 59,1 & 17,1 & 14,7 & 20,8 & 1465,4 \\
\hline
\end{tabular}

Fonte: Normais Climatológicas do Brasil 1961-1990.

Em anos de secas ocasionadas pela chamada "fase quente" do fenômeno Dipolo do Atlântico, ou seja, quando a temperatura do Atlântico Norte está mais quente que o normal e o Atlântico Tropical Sul está mais frio que o normal, a seca costuma atingir mais fortemente as terras que estão abaixo do paralelo de $5^{\circ} \mathrm{S}$.

Em termos de médias anuais de precipitação pluviométrica (Quadro 1), podemos perceber claramente que no Litoral Setentrional do Nordeste as taxas registradas decrescem de oeste para leste e de norte para o sul, ou seja, as estações no Estado do Maranhão registram o clima amazônico, com precipitações que chegam aos 2290 mm em São Luiz. Na Costa dos Deltas chegam a ser inferiores às da Costa da Dunas, como no caso de Fortaleza que registra cerca de $1609 \mathrm{~mm}$ anuais, contra os $1596 \mathrm{~mm}$ de Parnaíba, mesmo essa última estando mais próxima da linha do Equador. A diminuição da normal pluviométrica anual é mais nítida a partir dos $4^{\circ} \mathrm{S}$ na $\mathrm{CSB}$, caindo dos mais de $1600 \mathrm{~mm}$ anuais de Fortaleza $\left(3^{\circ} \mathrm{S}\right)$ para $862 \mathrm{~mm}$ em Jaguaruana $\left(4^{\circ} \mathrm{S}\right)$ e para $787 \mathrm{~mm}$ em Mossoró $\left(5^{\circ} \mathrm{S}\right)$. A redução é ainda mais drástica para Macau $\left(5^{\circ} \mathrm{S}\right)$, localizada aproximadamente no centro do Costa Branca. Nessa última cidade, o clima beira a aridez com pouco mais de $500 \mathrm{~mm}$ de precipitações anuais em média. Natal representa bem a retomada do clima úmido que domina o Nordeste Oriental (1465,4 mm/ano).

Na CSB, a estação chuvosa se inicia no mês de janeiro, estendendo-se até junho. Nas cidades mais chuvosas, é possível perceber que a ZCIT é claramente o principal sistema ocasionador de chuvas, sendo os meses de março-abril os mais chuvosos desde Parnaíba-PI, passando pelas cidades cearenses de Acaraú, Fortaleza e Jaguaruana, até chegar ao LSP em Mossoró e Macau. O mês de abril é o mais chuvoso no LSP.

A estação climatológica posicionada em um promontório que está aproximadamente no centro da Costa das Dunas em relação ao oceano da CSB, ou seja, em Fortaleza, registra que a estação chuvosa se estende desde janeiro até o mês de julho, sendo uma exceção em relação ao 
litoral em seu entorno, especialmente em relação à Costa Branca. As médias anuais de precipitação também são as mais elevadas superando os $1600 \mathrm{~mm}$, o que atribuímos exatamente à conformação geométrica desse trecho do litoral.

Macau que está no oposto a Fortaleza, ou seja, aproximadamente no centro do trecho mais côncavo em relação ao Atlântico representado pela Costa Branca da CSB, é a cidade que registra a menor estação chuvosa, apenas quatro meses (fevereiro a maio). Macau tem ainda a menor média anual de precipitação, uma vez que os 507 mm/ano em média são menos que um terço da média de chuvas de Fortaleza. A região de Macau tem a menor média mensal de precipitação em quase todos os meses em comparação com todas os outros trechos da CSB. Com base na análise desses dados, é possível afirmar conclusivamente que Macau é a cidade litorânea mais seca do Brasil, fato que nos permite concluir também que, do ponto de vista de totais pluviométricos, esse é o local mais indicado para a produção de sal marinho em todo o território brasileiro.

As Perturbações Ondulatórias no Campo dos Alísios (POA), por sua vez, são sistemas de mesoescala, elas ocorrem graças à penetração profunda de sistemas frontais do HN, em latitudes equatoriais. As POA se propagam para oeste, cruzam o equador, mas não se desenvolvem sobre o oceano. Porém, geralmente, intensificam-se quando chegam à costa devido ao aumento de convergência de umidade e ao contraste térmico continente-oceano (MOLION; BERNARDO, 2002). Em caso de associação entre POA com a brisa marítima, elas juntas chegam a penetrar 300 km para o interior do continente. Já em caso de confluírem com a brisa terrestre, podem provocar tempestades com precipitações superiores aos 50mm/dia, o que ocorre, geralmente, à noite.

As POA são fenômenos que ocorrem entre março e maio, quando originárias da África e entre junho e agosto quando provenientes do Atlântico Sul. São também chamadas de Distúrbios Ondulatórios de Leste (MACHADO et al. 2009) ou apenas "ondas de leste", e como seu nome sugere, são provenientes de leste, atingindo prioritariamente o litoral oriental do NEB, já que esse tem sua conformação frontal à rota do fenômeno. Esse fato também ocorre na Costa das Dunas da CSB já que este se apresenta em uma posição aproximadamente SE-NW, o que favorece a fenômenos de precipitação pluviométrica nas proximidades de Fortaleza. O trecho do litoral de Fortaleza apresenta, por conseguinte, consideráveis médias de precipitação nos meses de junho e julho (Quadro 1), inclusive superiores a Parnaíba que está mais ao norte, mas em um trecho côncavo e aproximadamente paralelo à atuação das POA. Nesses trechos côncavos em relação ao Oceano Atlântico, as POA atuam de forma bastante enfraquecida, no LSP, por exemplo, quando ocorrem precipitações associadas a esse fenômeno, elas são bem inferiores às do litoral oriental, pois as POA chegam primeiro a este, perdem umidade e só depois atingem o LSP.

Os fenômenos de brisa ajudam a diminuir ainda mais os totais pluviométricos da época de atuação das POA, registrados nos trechos côncavos do litoral, conforme explicado mais a frente. 
No que diz respeito à seca a variação é considerável (Quadro 2). Novamente é possível notar que no litoral do Maranhão o período seco é curto, apenas 4 meses, sendo menor ainda em Natal com 3 meses secos. Nas outras áreas temos uma estiagem mais prolongada. Ela costuma ser maior no trecho onde menos chove. Em Macau, tem-se normalmente 8 meses secos e outros dois meses com subseca. Os outros postos posicionados próximo a Macau (Costa Branca) têm 7 meses secos e um outro de subseca (Mossoró e Jaguaruana). Destaca-se novamente um comportamento diferenciado no trecho mais convexo da CSB, em Fortaleza tem-se, normalmente, apenas 5 meses de seca sem meses subsecos, menos que em Acaraú e Parnaíba que têm 6 meses secos e um de subseca em cada um, mesmo esses últimos estando posicionados em latitudes menores. Mais uma vez evidenciando que a conformação geométrica da costa em relação ao Oceano Atlântico é fator determinante no regime de precipitações na CSB.

Quadro 2: Número de meses secos $(\mathrm{P} \leq 2 \mathrm{~T})$, de subseca $(2 \mathrm{~T}<\mathrm{P} \leq 3 \mathrm{~T})$ e chuvosos $(3 \mathrm{~T}<\mathrm{P})$ em estações selecionadas.

\begin{tabular}{|c|c|c|c|}
\hline ESTAÇÕES & $\mathbf{P} \leq \mathbf{2 T}$ & $\mathbf{2 T}<\mathbf{P} \leq \mathbf{3 T}$ & $\mathbf{3 T}<\mathbf{P}$ \\
\hline Turiaçu - MA & 4 & 1 & 7 \\
\hline São Luís - MA & 4 & 1 & 7 \\
\hline Parnaíba - PI & 6 & 1 & 5 \\
\hline Acaraú - CE & 6 & 1 & 5 \\
\hline Fortaleza - CE & 5 & 0 & 7 \\
\hline Jaguaruana - CE & 7 & 1 & 4 \\
\hline Mossoró-RN & 7 & 1 & 4 \\
\hline Macau - RN & 8 & 2 & 2 \\
\hline Natal - RN & 3 & 2 & 7 \\
\hline
\end{tabular}

Fonte: Normais Climatológicas do Brasil 1961-1990.

Nesse aspecto, aparece novamente franca vantagem climatológica em termos de potencial para produção de sal marinho para a região de Macau. Nesse município, a soma de meses secos e subsecos chega a 10 meses do ano. O fato de ter uma estação seca maior propicia a possibilidade de se ter até 3 safras de extração de sal por ano, cada uma durando cerca de 3 a 4 meses. As outras regiões produtoras, mesmo na CSB, nem sempre podem extrair mais do que duas safras anuais, pois a chegada da estação chuvosa compromete as atividades e diminui a produtividade. Em anos de seca extrema no NNEB, a região de Macau registra totais pluviométricos anuais inexpressivos, podendo ser inferiores aos $100 \mathrm{~mm} /$ ano. A seca que é motivo de grande preocupação e desalento para a maior parte dos nordestinos, apresenta-se como uma vantagem produtiva para o setor salineiro, em especial no LSP.

No Quadro 3 apresenta-se o número de dias no mês e no ano de precipitações superiores a 1 mm em média. Pode-se observar que Fortaleza com 132 dias chuvosos em média, tem um padrão de frequência de chuvas muito mais próximo ao clima Equatorial Úmido de São Luís (130 dias 
chuvosos em média) e ao Tropical do Nordeste Oriental de Natal (126 dias chuvosos em média) do que ao de seu entorno semiárido. Observa-se também que na estação seca, nos meses de agosto e setembro, Fortaleza experimenta uma frequência de 5 dias chuvosos/mês, média superior inclusive à da capital maranhense. Mesmo no mês mais seco do ano (novembro), Fortaleza tem em média mais dias chuvoso (3) que as outras áreas do Nordeste Setentrional.

Quadro 3: Número de dias no mês e no ano com precipitação maior ou igual a $1 \mathrm{~mm}$ em média em estações selecionadas.

\begin{tabular}{|c|c|c|c|c|c|c|c|c|c|c|c|c|c|}
\hline Estações & JAN & FEV & MAR & ABR & MAI & JUN & JUL & AGO & SET & OUT & NOV & DEZ & Ano \\
\hline Turiaçu - MA & 13 & 19 & 21 & 21 & 21 & 16 & 15 & 7 & 3 & 2 & 2 & 5 & 145 \\
\hline São Luís - MA & 13 & 17 & 23 & 22 & 20 & 13 & 10 & 4 & 2 & 1 & 1 & 4 & 130 \\
\hline Parnaíba - PI & 8 & 15 & 18 & 18 & 15 & 6 & 4 & 0 & 0 & 1 & 1 & 4 & 90 \\
\hline Acaraú - CE & 10 & 13 & 20 & 19 & 12 & 7 & 7 & 1 & 1 & 1 & 1 & 2 & 94 \\
\hline Fortaleza - CE & 11 & 15 & 22 & 21 & 19 & 14 & 10 & 5 & 5 & 4 & 3 & 6 & 132 \\
\hline Jaguaruana - CE & 4 & 8 & 13 & 14 & 11 & 7 & 5 & 1 & 1 & 1 & 0 & 2 & 67 \\
\hline Macau - RN & 3 & 5 & 10 & 12 & 9 & 5 & 4 & 1 & 1 & 0 & 0 & 1 & 51 \\
\hline Natal - RN & 9 & 6 & 14 & 16 & 14 & 16 & 17 & 13 & 8 & 4 & 4 & 5 & 126 \\
\hline
\end{tabular}

Fonte: Normais Climatológicas do Brasil 1961-1990.

Atribui-se esta quantidade e frequência de dias chuvosos em Fortaleza durante os meses do ano ao fenômeno de brisa terrestre que se será abordado com mais detalhe em tópico próprio $a$ posteriori. Contrariamente a Fortaleza, as cidades localizadas nos trechos côncavos do litoral têm uma quantidade média de dias chuvosos durante o ano bem inferior a Fortaleza, como em Parnaíba com 90 dias/ano e, principalmente em Macau, que tem apenas 51 dias chuvosos, em média, durante o ano. A partir do mês de junho, os dias chuvosos em Macau diminuem drasticamente, chovendo em média apenas 5 dias em junho e 4 em julho. De agosto a dezembro, o total de dias chuvosos somados é de apenas 3, ou seja, em 150 dias corridos chovem em 3 deles em média. Esse fato contribui positivamente para o potencial produtivo da região salineira de Macau.

$\mathrm{Na}$ CSB, o número de dias chuvosos decresce de modo geral de Noroeste para Sudeste, seguindo a diminuição da longitude e o aumento da latitude, havendo a exceção de Fortaleza no extremo convexo do Costa das Dunas. Macau novamente aparece como cidade mais seca, com apenas 51 dias chuvosos, durante o ano em média, o que também representa melhores condicionantes climáticos para a produção de sal marinho no Costa Branca. Com menos dias chuvosos tem-se, por consequência, mais dias de plena evaporação de água nos tanques das salinas.

Além de analisar as médias das normais de precipitação, verificou-se a quantidade de anos chuvosos no período da normal climatológica. De acordo com os dados de precipitação pluviométrica da SUDENE (1990) as médias de precipitação pluviométrica calculadas para o período de 1961 a 1990 foram de 725,3 mm em Areia Branca e de 949 mm em Jaguaruana (Quadro 4). 
Quadro 4: Precipitação média; anos chuvosos, normais e secos em Jaguaruana e Areia Branca.

\begin{tabular}{|l|l|l|l|l|}
\hline Postos & Anos chuvosos & Anos normais & Anos secos & Precipitação média \\
\hline Jaguaruana* & 10 & 7 & 13 & 949 \\
\hline Areia Branca & 11 & 4 & 15 & 725,3 \\
\hline
\end{tabular}

Fonte: SUDENE (1990). *não há dados para o ano de 1976,

ele foi estimado como sendo ano seco com base no histórico e na informação de outras estações.

É possível perceber com os dados que há uma grande inconstância das chuvas na região produtora, principalmente, em Areia Branca, que apresentou apenas quatro anos de chuvas normais em um período de 30 anos. Os anos de chuvas próximos ou abaixo da média são os melhores para a produção de sal marinho. Ao analisar os dados é notável que a maior parte dos anos é favorável à atividade salineira, já que a cada 30 anos, 15 anos são de seca e apenas 11 em cada 30 anos são considerados chuvosos em Areia Branca. Na região de Jaguaruana as condições são similares, temse apenas 10 em cada 30 anos chuvosos, sete anos com pluviometria normal e 13 anos secos em uma série de 30 anos.

\subsection{Do regime de ventos}

Para o caso da CSB, os principais fatores geradores de ventos sinóticos são os anticiclones do Hemisfério Norte (ASAN) e do Hemisfério Sul (ASAS). Essas duas zonas de alta pressão sopram os ventos, conhecidos como Alísios, quase que de forma incessante em direção às baixas pressões equatoriais ao longo do ano. Esses ventos convergem para uma área de latitude variável conhecida como Zona de Convergência dos Alísios (ZCA), sendo essa uma das variáveis meteorológicas que compõe o principal sistema gerador de chuvas na CSB, a ZCIT. Devido à atuação desses dois anticliclones, os ventos na CSB são predominantemente de Sudeste, Leste ou Nordeste, a depender da latitude do lugar (Quadros 5 e 6).

Quadro 5: Direção resultante do vento (graus) média durante os meses e ano em estações selecionadas

\begin{tabular}{|l|c|c|c|c|c|c|c|c|c|c|c|c|c|}
\hline \multicolumn{1}{|c|}{ Estações } & JAN & FEV & MAR & ABR & MAI & JUN & JUL & AGO & SET & OUT & NOV & DEZ & Ano \\
\hline São Luís - MA & 56 & 52 & 48 & 50 & 63 & 71 & 68 & 62 & 56 & 55 & 54 & 54 & 57 \\
\hline Fortaleza - CE & 94 & 95 & 104 & 109 & 119 & 122 & 118 & 107 & 100 & 95 & 89 & 91 & 101 \\
\hline Macau - RN & 81 & 87 & 91 & 99 & 109 & 114 & 120 & 111 & 101 & 86 & 78 & 78 & 95 \\
\hline Natal - RN & 117 & 121 & 122 & 135 & 146 & 149 & 152 & 145 & 136 & 124 & 118 & 115 & 132 \\
\hline
\end{tabular}

. Fonte: Normais Climatológicas do Brasil 1961-1990. 
Quadro 6: Direção predominante do vento (pontos cardeais e colaterais) média durante os meses e ano em estações selecionadas.

\begin{tabular}{|l|c|c|c|c|c|c|c|c|c|c|c|c|c|}
\hline \multicolumn{1}{|c|}{ Estações } & JAN & FEV & MAR & ABR & MAI & JUN & JUL & AGO & SET & OUT & NOV & DEZ & Ano \\
\hline São Luís - MA & NE & NE & NE & Calmo & Calmo & E & NE & NE & NE & NE & NE & NE & NE \\
\hline Fortaleza - CE & E & E & Calmo & Calmo & Calmo & E & E & E & E & E & E & E & E \\
\hline Macau - RN & E & E & E & SE & SE & SE & SE & SE & SE & E & NE & E & SE \\
\hline Natal - RN & SE & SE & SE & SE & SE & SE & SE & SE & SE & SE & SE & E & SE \\
\hline
\end{tabular}

Fonte: Normais Climatológicas do Brasil 1961-1990.

Percebe-se que nas latitudes mais setentrionais os ventos têm direção predominante de Nordeste, como em São Luiz que está a apenas $1^{\circ}$ de latitude sul. Já em um trecho intermediário da $\mathrm{CSB}$, em Fortaleza $\left(3^{\circ} \mathrm{S}\right)$, os ventos são predominantes de leste. Essa cidade estaria sob influência tanto dos Alísios de nordeste como dos de sudeste, no mês de junho, por exemplo, a direção predominante chega a ser de $122^{\circ}$ (Quadro 5), mostrando a influência maior do ASAS. Já em Macau, localizada aos $5^{\circ} \mathrm{S}$, os ventos são predominantes de sudeste, portanto, esse trecho do LSP está sob maior influência do ASAS, entretanto entre outubro e março a direção predominante é leste, chegando a ser nordeste em novembro (Quadro 6), época de forte atuação do ASAN.

Em Macau, considere-se que a atuação do fenômeno de brisa marítima tende a impulsionar os ventos no sentido norte-sul, assim como as brisas terrestres trabalham no sentido sul-norte. Isso se deve à linha de costa nessa área ser quase que paralela ao Equador. As brisas de terra-mar nessa área tendem a ser intensificadas, especialmente, no mês mais quente e mais seco do ano (novembro), quando o gradiente de pressão entre continente e oceano é maior, ajudando a explicar a direção resultante do vento no sentido Nordeste no mês de novembro.

A predominância dos ventos Alísios de sudeste é mais um fator que explica muito bem o clima mais seco no LSP, pois as massas de ar que influenciam o NEB são empurradas pelos ventos de SE, ganham umidade sobre o oceano e levam nuvens de tempo ruim para o litoral oriental do NEB. Ao chegarem ao LSP os ventos trazem consigo massas de ar que já perderam muito de sua umidade, isso porque grande parte dessa umidade, adquirida no oceano, condensa e se transforma em precipitação pluviométrica ao entrar em contato com o continente, o que ocorre primeiramente no litoral oriental, para só depois atingirem o LSP, que está assim numa espécie de "abrigo" em relação aos sistemas promotores de chuvas de SE, sendo esse um fator importante para explicar as reduzidas taxas de precipitações no LSP, em especial, em Macau

Em termos de variação diária, é interessante perceber que nos trechos côncavos é comum que o vento mude de direção de forma mais acentuada do que na parte mais convexa do litoral. No Quadro 7, apresenta-se de forma ilustrativa a direção e velocidade dos ventos no dia 29/05/2012 que representa bem o que ocorre costumeiramente na CSB. 
Quadro 7: Velocidade (m/s), direção (graus) e rajadas (m/s) de vento em Macau, Fortaleza e Parnaíba em horas UTC (sigla em inglês para tempo universal coordenado) no dia 29/05/2012.

Em destaque cinza os ventos de nordeste.

\begin{tabular}{|c|c|c|c|c|c|c|c|c|c|}
\hline & \multicolumn{3}{|c|}{ MACAU } & \multicolumn{3}{|c|}{ FORTALEZA } & \multicolumn{3}{|c|}{ PARNAÍBA } \\
\hline UTC & Vel. & Dir. & Raj. & Vel. & Dir. & Raj. & Vel. & Dir. & Raj. \\
\hline $\mathbf{0 0}$ & 4.2 & $113^{\circ}$ & 8.0 & 1.6 & $115^{\circ}$ & 5.3 & 1.9 & $63^{\circ}$ & 5.9 \\
\hline 01 & 3.1 & $120^{\circ}$ & 7.0 & 2.2 & $108^{\circ}$ & 4.8 & 1.7 & $78^{\circ}$ & 4.4 \\
\hline $\mathbf{0 2}$ & 2.9 & $122^{\circ}$ & 5.9 & 2.0 & $107^{\circ}$ & 5.0 & 2.9 & $71^{\circ}$ & 5.6 \\
\hline $\mathbf{0 3}$ & 2.4 & $127^{\circ}$ & 5.0 & 1.9 & $121^{\circ}$ & 5.1 & 2.4 & $65^{\circ}$ & 5.8 \\
\hline 04 & 2.4 & $136^{\circ}$ & 3.5 & 0.9 & $192^{\circ}$ & 4.5 & 2.1 & $81^{\circ}$ & 4.5 \\
\hline 05 & 1.9 & $141^{\circ}$ & 3.1 & 1.0 & $181^{\circ}$ & 2.1 & 1.6 & $93^{\circ}$ & 3.3 \\
\hline 06 & 1.8 & $164^{\circ}$ & 2.5 & 0.8 & $167^{\circ}$ & 2.2 & 1.6 & $104^{\circ}$ & 4.3 \\
\hline $\mathbf{0 7}$ & 2.4 & $180^{\circ}$ & 2.8 & 1.1 & $182^{\circ}$ & 2.3 & 1.8 & $107^{\circ}$ & 3.4 \\
\hline 08 & 2.3 & $165^{\circ}$ & 2.8 & 1.6 & $183^{\circ}$ & 3.3 & 1.6 & $116^{\circ}$ & 3.0 \\
\hline 09 & 2.0 & $183^{\circ}$ & 2.7 & 2.0 & $185^{\circ}$ & 3.8 & 1.4 & $99^{\circ}$ & 3.1 \\
\hline 10 & 2.4 & $135^{\circ}$ & 4.0 & 2.3 & $176^{\circ}$ & 5.5 & 2.6 & $79^{\circ}$ & 4.9 \\
\hline 11 & 5.3 & $109^{\circ}$ & 8.7 & 3.1 & $164^{\circ}$ & 7.2 & 3.6 & $90^{\circ}$ & 6.6 \\
\hline 12 & 5.9 & $103^{\circ}$ & 10.4 & 3.2 & $135^{\circ}$ & 8.7 & 4.7 & $94^{\circ}$ & 8.3 \\
\hline 13 & 5.3 & $112^{\circ}$ & 9.7 & 3.5 & $128^{\circ}$ & 8.7 & 4.5 & $105^{\circ}$ & 10.1 \\
\hline 14 & 5.7 & $48^{\circ}$ & 9.5 & 4.6 & $115^{\circ}$ & 9.5 & 5.7 & $92^{\circ}$ & 9.7 \\
\hline 15 & 6.5 & $47^{\circ}$ & 10.1 & 4.0 & $110^{\circ}$ & 9.2 & 5.3 & $77^{\circ}$ & 9.2 \\
\hline 16 & 7.4 & $50^{\circ}$ & 11.6 & 4.9 & $104^{\circ}$ & 9.1 & 5.0 & $101^{\circ}$ & 9.4 \\
\hline 17 & 7.8 & $50^{\circ}$ & 12.3 & 4.4 & $113^{\circ}$ & 9.3 & 3.7 & $98^{\circ}$ & 7.9 \\
\hline 18 & 7.8 & $67^{\circ}$ & 13.1 & 4.2 & $103^{\circ}$ & 9.1 & 4.9 & $36^{\circ}$ & 9.6 \\
\hline 19 & 6.6 & $63^{\circ}$ & 12.6 & 2.9 & $106^{\circ}$ & 9.6 & 4.7 & $51^{\circ}$ & 10.8 \\
\hline 20 & 5.7 & $67^{\circ}$ & 12.1 & 3.5 & $100^{\circ}$ & 7.8 & 4.5 & $51^{\circ}$ & 8.9 \\
\hline 21 & 5.5 & $100^{\circ}$ & 10.5 & 2.3 & $101^{\circ}$ & 6.4 & 4.0 & $56^{\circ}$ & 8.9 \\
\hline 22 & 4.0 & $96^{\circ}$ & 9.0 & 2.7 & $99^{\circ}$ & 5.9 & 3.7 & $65^{\circ}$ & 8.4 \\
\hline 23 & 4.2 & $100^{\circ}$ & 8.5 & 2.2 & $100^{\circ}$ & 5.9 & 3.7 & $68^{\circ}$ & 8.0 \\
\hline
\end{tabular}

Fonte: <http://www.inmet.gov.br/portal/index.php?r=estacoes/estacoesAutomaticas> acesso em 11/07/12.

Em Macau que fica na Costa Branca, o vento teve direção entre sudeste e sul entre 00 UTC e 10 UTC, passou rapidamente para uma tendência entre sudeste e leste entre 11 UTC e 13 UTC. Entre 14 UTC e 20 UTC teve direção nordeste, passando a leste novamente entre 21 UTC e 23 UTC. O dia 29/05/2012 mostra a tendência geral dos ventos sudeste, e em menor escala leste, ou seja, os ventos sopram mais do continente que do oceano. Os ventos nordeste, (provenientes do Atlântico) por sua vez, só se apresentam durante o período de atuação da brisa marinha (entre $11 \mathrm{~h}$ e 17h no horário local no exemplo citado), ou seja, quando a terra se encontra mais aquecida que o oceano. Esse é também o período onde ocorrem os maiores índices de precipitação pluviométrica.

Em Parnaíba, que fica na Costa dos Deltas ocorreu algo semelhante, porém as mudanças na direção dos ventos foram menos sensíveis e atribuímos isso à menor concavidade do litoral, pois nessa estação os ventos se alternaram entre leste e nordeste.

No mesmo dia, em Fortaleza (trecho convexo do litoral), excetuando o período entre 04 UTC e 11 UTC em que o vento foi predominante sul (brisa terrestre), a direção predominante foi leste, ou seja, procedente do oceano. O fluxo da brisa terrestre tende a convergir com os Alísios, o que provoca, com frequência, precipitações nesse trecho da CSB, no período noturno e nas madrugadas. Os ventos alísios são, portanto, importantes para a compreensão da atuação dos 
sistemas atmosféricos de grande escala, entretanto, existem fenômenos de mesoescala que são controlados por outros tipos de vento, nesse caso as brisas.

Usualmente é atribuída maior relevância ao fenômeno da brisa marítima, pois esta costuma carregar umidade do oceano para o interior do continente até distâncias de cerca de $300 \mathrm{~km}$. Ao contrário, a brisa terrestre costuma provocar precipitações sobre o oceano. Entretanto, em estudo clássico Kousky (1980) percebeu que áreas costeiras do NEB (especialmente no trecho oriental) experimentam o máximo de precipitação no período noturno (entre $21 \mathrm{~h}$ e $9 \mathrm{~h}$ no horário local). Isso ocorreria "devido à convergência entre o fluxo médio de ar próximo à superfície procedente do oceano, e o fluxo superficial do continente para o mar devido à brisa terrestre" (TEIXEIRA, 2008, p. 283). Nas áreas entre 150-300 km para o interior, o máximo de precipitação seria registrado entre $15 \mathrm{~h}$ e $21 \mathrm{~h}$ local.

Kousky (1980) identificou ainda que o fenômeno de brisa atua na CSB, provocando máximos diurnos de precipitação entre $21 \mathrm{~h}$ e $09 \mathrm{~h}$ no trecho mais convexo da CSB.

O Fenômeno pode ser visualizado em imagens de satélite com considerável frequência. Na figura 2 é possível visualizar o evento aqui analisado, sendo possível ainda visualizar a formação de dois arcos de nuvens sobre o oceano à norte dos dois trechos côncavos da CSB.

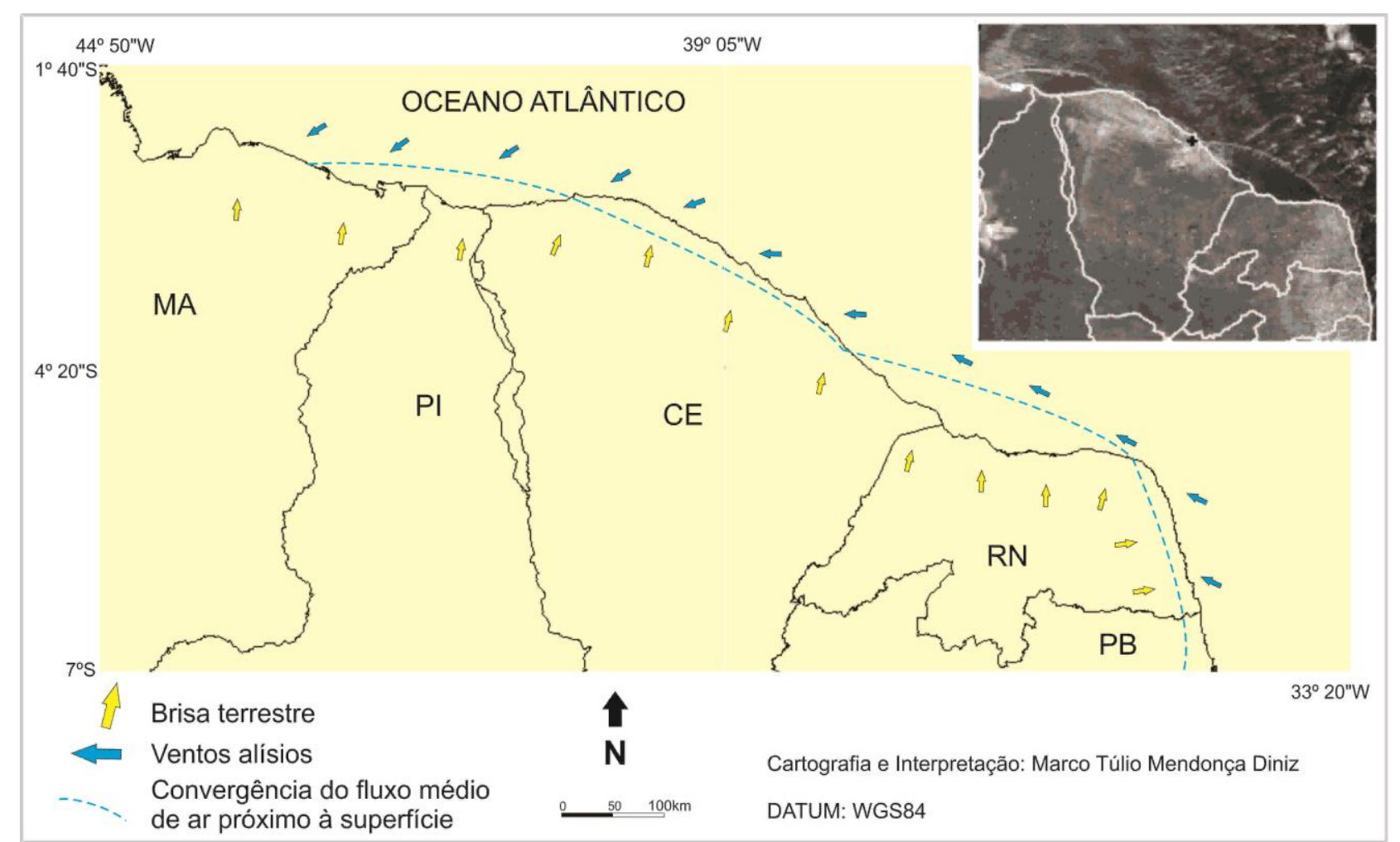

Figura 2: Fluxo médio do ar próximo à superfície no Litoral do Nordeste em face de brisa terrestre (à noite). No canto superior direito, pode ser visualizada imagem NOAA-14, 19/01/2007, 8h35min local, mostrando linhas de nuvens associadas a brisas terrestres. Fortaleza é marcada como uma pequena cruz.

Fonte: Imagem editada por Teixeira (2008). 
Para comprovar a teoria de Kousky (1980), foram analisados os eventos de precipitação em um ano de chuva próximo à média. No ano de 1996 o total registrado em Macau foi de $550 \mathrm{~mm}$, em Fortaleza de 1646,3 mm e em Parnaíba de 1598,8 mm, apenas um pouco acima das normais para cada estação.

Nos gráficos 1, 2 e 3 é possível perceber que nas três estações analisadas, apenas a de Fortaleza (que está localizada no treco convexo do litoral), tem predominância de chuvas no período da noite e madrugada, assim como é possível observar que em Macau e Parnaíba (trechos côncavos do litoral) a predominância de chuvas ocorre durante o dia. É interessante ressaltar que em Fortaleza o evento de maior precipitação no ano também foi registrado entre a noite e o início da manhã com 108,2 mm em 26/02/1996, às 09h local, assim como o evento de maior precipitação em Macau foi registrado no período da tarde com 48,8 mm, em 20/04/1996, às 15h local. Em Parnaíba, o máximo foi registrado no início da noite com 87,2 mm, em 17/01/1996, às 21h local.

Gráfico 1: Precipitação em milímetros por dias e hora de registro na estação de Macau no ano de 1996.

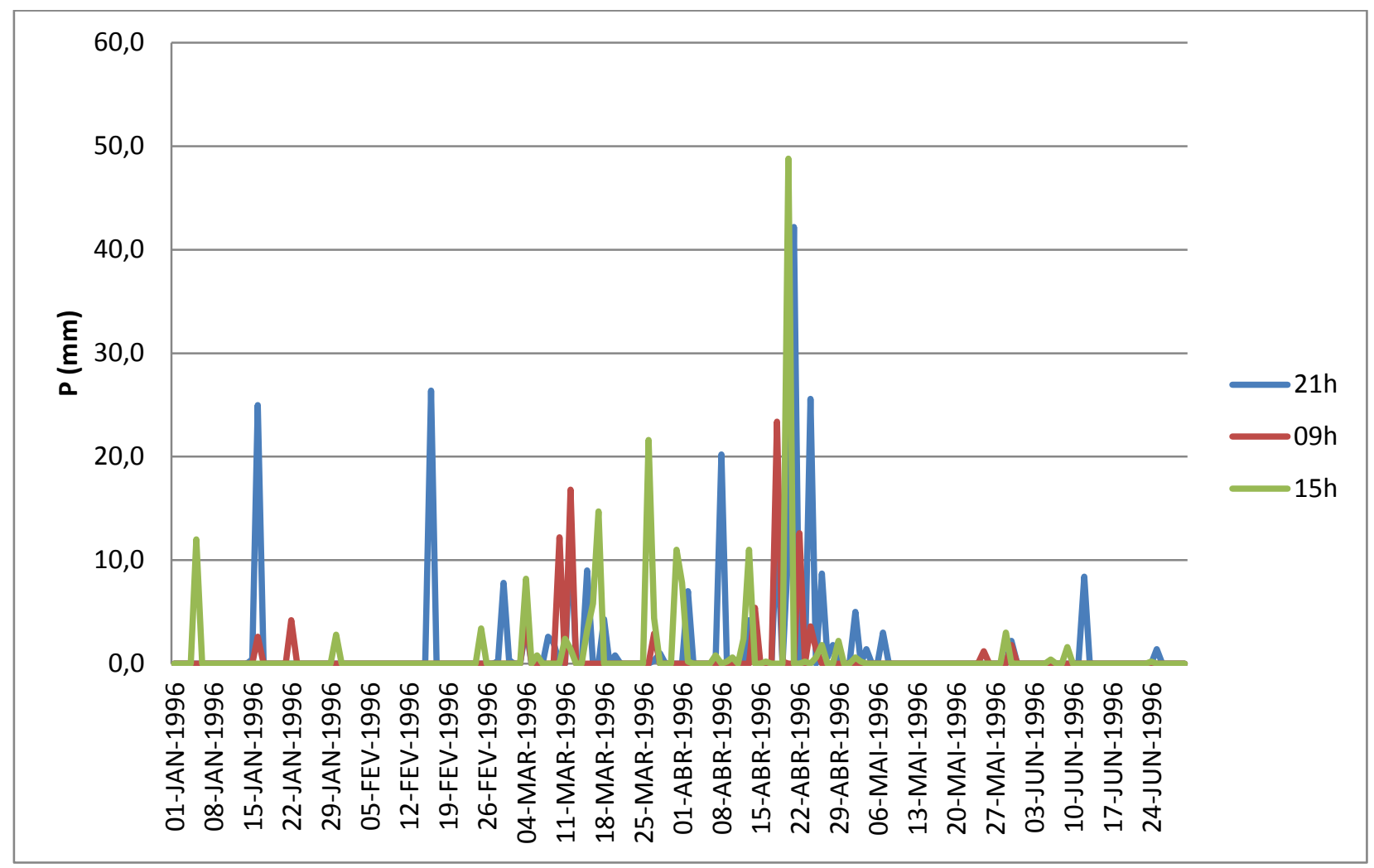

Fonte: Dados fornecidos pelo INMET. 
Gráfico 2: Precipitação em milímetros por dias e hora de registro na estação de Fortaleza no ano de 1996.

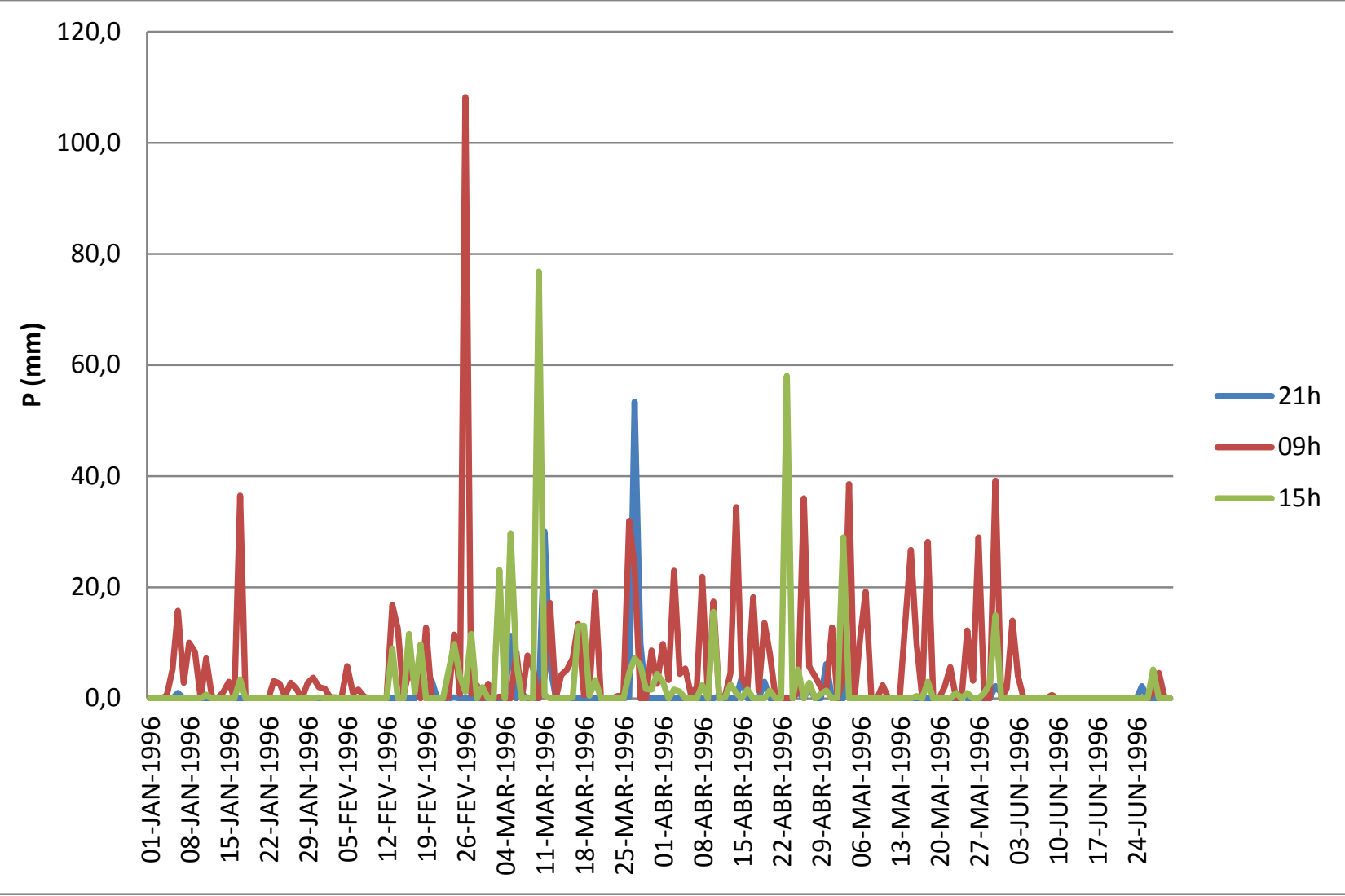

Fonte: Dados fornecidos pelo INMET.

Gráfico 3: Precipitação em milímetros por dias e hora de registro na estação de Parnaíba no ano de 1996.

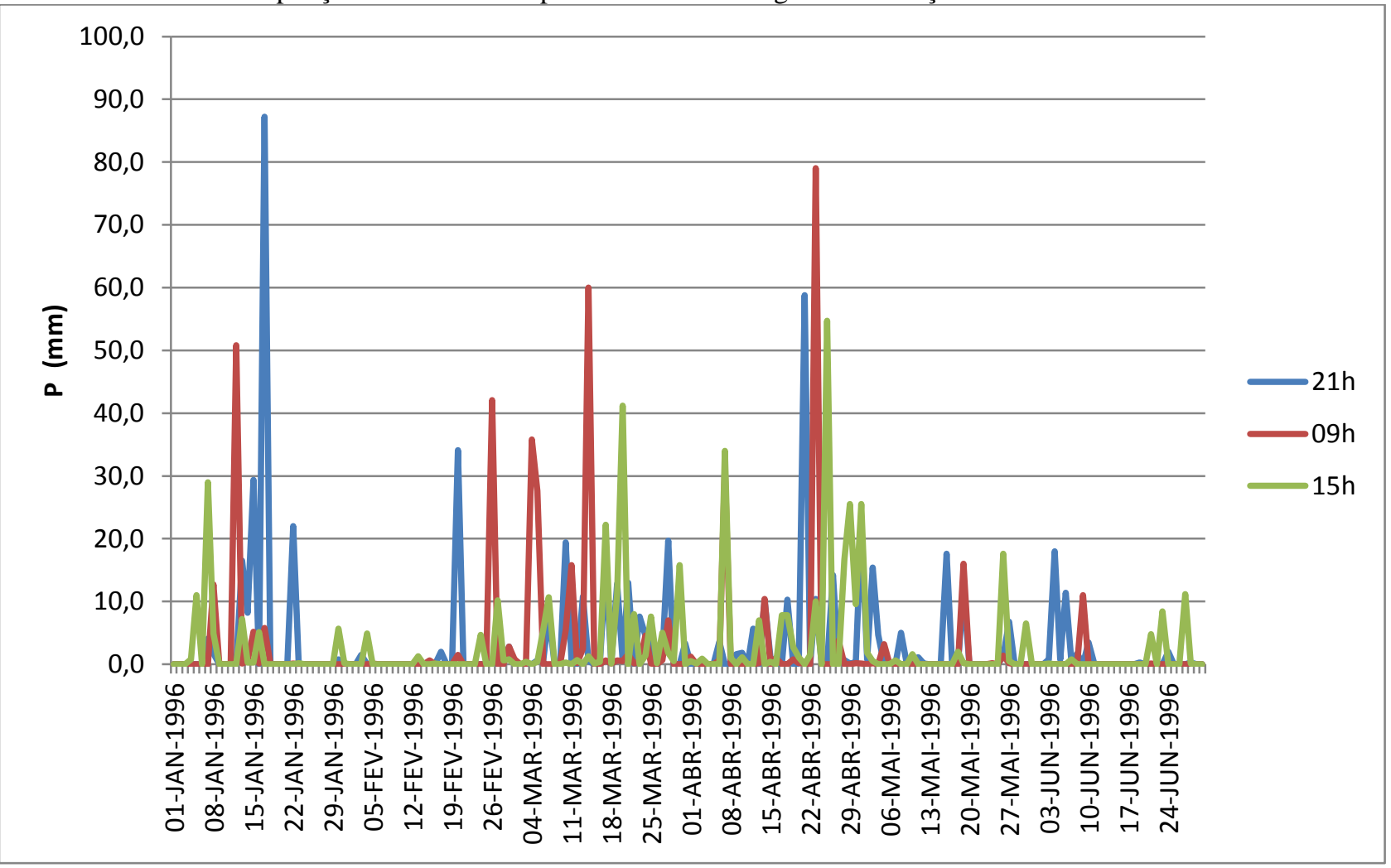


Fonte: Dados fornecidos pelo INMET.

No quadro 8, é possível observar de forma quantitativa a concentração dos eventos de precipitação pluviométrica. Em Fortaleza, foram registrados 1071,3 mm entre às $21 \mathrm{~h}$ e às 09h local, o que representa mais de $65 \%$ do total. As chuvas registradas entre as $21 \mathrm{~h}$ e as $09 \mathrm{~h}$ representam apenas 28,6 \% em Parnaíba e 18,1 \% em Macau. Para esses últimos, a maior parte da precipitação pluviométrica é percebida no período diurno. É interessante salientar, que a maior concavidade do Costa Branca representado por Macau faz com que esse tenha maior concentração das chuvas durante o dia que o Costa dos Deltas é representado por Parnaíba.

Quadro 8: Concentração do total de precipitação em milímetros (mm) e percentual (\%)

\begin{tabular}{|c|c|c|c|c|c|c|c|c|c|c|}
\hline por horário em estações selecionadas no ano de 1996. \\
\hline Estação & \multicolumn{3}{|c|}{ MACAU } & \multicolumn{3}{c|}{ FORTALEZA } & \multicolumn{3}{c|}{ PARNAÍBA } \\
\hline Hora local & $21 \mathrm{~h}$ & $09 \mathrm{~h}$ & $15 \mathrm{~h}$ & $21 \mathrm{~h}$ & $09 \mathrm{~h}$ & $15 \mathrm{~h}$ & $21 \mathrm{~h}$ & $09 \mathrm{~h}$ & $15 \mathrm{~h}$ \\
\hline P (mm) 10 semestre & 253,2 & 92,5 & 174,5 & 144,1 & 967,0 & 418,8 & 579,7 & 448,4 & 486,7 \\
\hline P (mm) ano & 272,2 & 99,3 & 178,5 & 145,6 & 1071,3 & 429,4 & 651,3 & 458,1 & 489,4 \\
\hline P(\%) ano & 49,5 & 18,1 & 32,4 & 8,9 & 65,1 & 26 & 40,7 & 28,6 & 30,6 \\
\hline
\end{tabular}

Fonte: Dados fornecidos pelo INMET.

Como dito anteriormente, a brisa marítima não favorece aos eventos de chuvas próximas à costa e sim no interior, e comumente os eventos de brisa terrestre provocam chuvas sobre o oceano, porém a concavidade da Costa Branca faz com que a convergência em baixos níveis da brisa terrestre com os ventos sinóticos (Alísios de sudeste) origine uma frente de brisa "no oceano, que dá origem em geral, a nuvens dispostas na forma de um grande arco com concavidade contrária à concavidade da costa" (TEIXEIRA, 2008, p. 287; Figura 8). Ocorre que a extremidade oeste da frente de brisa comumente se posiciona sobre Fortaleza, favorecendo a formação de nuvens e ocorrências de chuvas fracas durante a madrugada e início da amanhã, para só depois continuar seu trajeto em direção ao oceano.

Desse modo o fenômeno de brisa terrestre concorreria para o aumento na frequência de precipitação em Fortaleza e nas demais cidades litorâneas vizinhas da Costa das Dunas, conforme mencionado, anteriormente. A brisa terrestre é, portanto, um fator que concorre para o aumento das precipitações no trecho convexo, principalmente em Fortaleza, fazendo com que esse litoral seja o mais chuvoso do Estado do Ceará e da CSB.

Além de registrar as maiores médias de precipitação, Fortaleza registra, em média, 132 dias chuvosos durante o ano (Quadro 4), muito superior à média das outras áreas da CSB. De modo contrário, as regiões produtoras de sal próximas a Mossoró e Macau, são extremamente desfavorecidas do ponto de vista de precipitação pelo fenômeno da brisa terrestre, que tende a afastar os ventos sinóticos da costa, gerando convergência de nuvens de chuva sobre os oceanos, o 
que diminui seus totais pluviométricos, assim como a frequência de chuvas, tornando-se mais um fator de aumento da produtividade de sal marinho para a região. Pode-se inclusive afirmar que a maritimidade é um elemento que concorre para diminuição dos totais pluviométricos no LSP.

Além da direção dos ventos, é preciso analisar sua intensidade, isso porque a velocidade dos ventos influencia em outro importante elemento do clima - a evaporação. No que diz respeito à velocidade dos ventos há que se considerar que eles são mais velozes na superfície, tanto sejam menores os obstáculos que se apresentem, já que:

\begin{abstract}
A rugosidade do solo é um fator redutor da velocidade dos ventos em superfície, uma vez que desempenha um efeito de fricção sobre os ventos. Assim, os oceanos favorecem a formação de ventos velozes, enquanto os continentes, devido à heterogeneidade da cobertura de sua superfície (vegetação, presença de cidades) e às suas características geomorfológicas, tendem a reduzi-la (MENDONÇA ; DANNI-OLIVEIRA, 2007, p. 77, grifos dos autores).
\end{abstract}

No quadro 9, é possível perceber que em Macau os ventos em média são muito mais velozes que no restante do Litoral Setentrional do Nordeste, chegando a ser mais de duas vezes mais velozes que em São Luís. Isso se deve à sua geomorfologia que é extremamente plana, apresentando em uma área de mais de mais de $30 \mathrm{~km}$ de largura uma variação de altitude de no máximo $1 \mathrm{~m}$. Acrescente-se a isso, o fato de que praticamente não há vegetação nessa vasta planície hipersalina, pois o que predomina na área do delta do rio Piranhas-Açu são as salinas e seus tanques de evaporação e cristalização. Esses dois fatores juntos fazem com que praticamente não haja rugosidade ou obstáculos na região, o que proporciona aos ventos manter e, em alguns casos, até ganhar velocidade, principalmente em fase de brisa marinha (Quadro 9), quando costumeiramente têm-se rajadas de ventos superiores aos $14 \mathrm{~m} / \mathrm{s}$, fato que se deve ao grande gradiente térmico terramar. Os intensos e constantes ventos que sopram livremente são outro fator que contribui para o aumento do potencial produtivo para sal marinho na região de Macau.

Quadro 9: Velocidade média do vento (m/s) em São Luís, Fortaleza e Macau.

\begin{tabular}{|c|c|c|c|c|c|c|c|c|c|c|c|c|c|}
\hline Estações & JAN & FEV & MAR & ABR & MAI & JUN & JUL & AGO & SET & OUT & NOV & DEZ & Ano \\
\hline São Luís - MA & 2,49 & 2,03 & 1,82 & 1,51 & 1,65 & 1,88 & 2,18 & 2,93 & 3,61 & 3,90 & 3,93 & 3,36 & 2,61 \\
\hline Fortaleza - CE & 3,13 & 2,58 & 2,13 & 2,02 & 2,25 & 2,70 & 3,20 & 3,89 & 4,55 & 4,10 & 4,07 & 3,96 & 3,21 \\
\hline Macau - RN & 5,95 & 5,55 & 4,71 & 4,29 & 4,74 & 5,12 & 5,53 & 6.60 & 6.92 & 6,84 & 6,69 & 6,29 & 5,77 \\
\hline
\end{tabular}

Fonte: Normais Climatológicas do Brasil 1961-1990.

\title{
3.3. Das temperaturas
}

Ao contrário das precipitações, a variação de temperatura na CSB é muito pequena (Quadro 10), os fatores latitude e altitude são os que se impõe nessa normal. 
Quadro 10 - Temperatura média compensada $\left({ }^{\circ} \mathrm{C}\right)$ em estações selecionadas.

\begin{tabular}{|l|c|c|c|c|c|c|c|c|c|c|c|c|c|}
\hline Estações & JAN & FEV & MAR & ABR & MAI & JUN & JUL & AGO & SET & OUT & NOV & DEZ & Ano \\
\hline São Luís - MA & 26,1 & 25,7 & 25,6 & 25,8 & 25,9 & 25,9 & 25,6 & 25,9 & 26,3 & 26,6 & 26,9 & 26,7 & 26,1 \\
\hline Fortaleza - CE & 27,1 & 26,9 & 26,4 & 26,2 & 26,2 & 25,8 & 25,6 & 26,0 & 26,4 & 26,9 & 27,2 & 27,3 & 26,6 \\
\hline Macau - RN & 27,4 & 27,3 & 27,0 & 27,1 & 27,0 & 26,3 & 25,9 & 26,2 & 26,6 & 26,5 & 26,9 & 27,2 & 26,8 \\
\hline Natal - RN & 27,0 & 27,2 & 27,0 & 26,6 & 26,0 & 24,9 & 24,3 & 24,3 & 25,1 & 26,0 & 26,4 & 26,7 & 26,0 \\
\hline
\end{tabular}

Fonte: Normais Climatológicas do Brasil 1961-1990.

\subsection{Da pressão atmosférica}

Em termos de pressão atmosférica a latitude ao nível do mar é o fator predominante não havendo, portanto, em termos de produtividade para sal marinho, vantagem para nenhuma área da CSB (Quadro 11).

Quadro 11: Pressão atmosférica ao nível do barômetro (hPa).

\begin{tabular}{|c|c|c|c|c|c|c|c|c|c|c|c|c|c|}
\hline Estações & JAN & FEV & MAR & ABR & MAI & JUN & JUL & AGO & SET & OUT & NOV & DEZ & Ano \\
\hline Tur & & 1003,8 & & 10 & & 100 & 1006,1 & 1005,7 & 1005,2 & 2 & 5 & 1003,4 & 1004,5 \\
\hline São Luís & 1004,4 & 1004,4 & 1004,5 & 1004,6 & 1005,2 & 1006,2 & 1006,8 & 1006,3 & 1005,8 & 1004,8 & 1004,1 & 1004,0 & 1005,1 \\
\hline Fort & 1007,4 & 1007,5 & 1007,6 & 1007,8 & 1008,5 & 1009,9 & 1010,6 & 1010,0 & 1009,9 & 1008,7 & 1008,2 & 1007,8 & 1008,7 \\
\hline Jaguaruana & 1009,0 & 1009,0 & 1008,9 & 1009,2 & 1010,1 & 1011,5 & 1012,1 & 1011,7 & 1011,1 & 1009,9 & 1009,3 & 1009,1 & 1010,1 \\
\hline Mac & 1010,5 & 1010,3 & 1010,7 & 1010,6 & 1011,2 & 1012,6 & 1013,0 & 1013,6 & 1012,8 & 1011,7 & 1010,8 & 1010,5 & 1011,5 \\
\hline
\end{tabular}

Fonte: Normais Climatológicas do Brasil 1961-1990.

\subsection{Da insolação}

Em termos de taxa de insolação, assim como nas variáveis anteriores, esta também não apresenta diferenças consideráveis (Quadro 12). De todo modo, esse elemento não faz com que haja em Macau (que tem menor insolação) menores taxas de evaporação que as demais regiões da CSB, conforme vê-se mais à frente.

Quadro 12: Insolação total (horas) na CSB.

\begin{tabular}{|c|c|c|c|c|c|c|c|c|c|c|c|c|c|}
\hline Estações & JAN & FEV & MAR & ABR & MAI & JUN & JUL & AGO & SET & OUT & NOV & DEZ & Ano \\
\hline Turiaçu - MA & 154,0 & 117,1 & 109,8 & 113,0 & 148,3 & 190,9 & 218,7 & 251,2 & 245,7 & 242,2 & 226,8 & 206,8 & 2224,5 \\
\hline São Luís - MA & 152,6 & 113,7 & 107,2 & 113,7 & 162,6 & 213,1 & 237,6 & 260,3 & 249,9 & 251,8 & 244,1 & 206,3 & 2312,9 \\
\hline Parnaíba-PI & 209,5 & 166,4 & 172,0 & 198,5 & 221,2 & 255,6 & 281,8 & 309,7 & 299,3 & 303,1 & 289,8 & 249,3 & 2956,2 \\
\hline Acaraú - CE & 209,5 & 150,1 & 148,6 & 157,1 & 216,2 & 231,0 & 266,0 & 290,0 & 287,2 & 300,2 & 285,7 & 258,2 & 2799,8 \\
\hline Fortaleza-CE & 225,2 & 182,3 & 150,0 & 157,1 & 208,4 & 238,7 & 268,3 & 295,9 & 281,6 & 291,4 & 282,2 & 262,3 & 2843,4 \\
\hline Jaguaruana - CE & 255,3 & 194,4 & 180,4 & 198,9 & 220,7 & 231,8 & 249,5 & 280,5 & 280,1 & 296,8 & 285,7 & 275,1 & 2949,2 \\
\hline Mossoró-RN & 231,7 & 194,4 & 186,4 & 190,3 & 217,1 & 211,3 & 228,3 & 269,1 & 271,7 & 290,3 & 281 & 256,5 & 2828,1 \\
\hline Macau - RN & 229,2 & 196,5 & 188,0 & 202,1 & 202,3 & 206,0 & 210,5 & 248,8 & 252,3 & 277,8 & 249,6 & 222,5 & 2685,6 \\
\hline
\end{tabular}

Fonte: Normais Climatológicas do Brasil 1961-1990. 


\subsection{Da nebulosidade}

Em termos de nebulosidade percebe-se uma maior constância em Macau, que tem média inferior à de Fortaleza nos meses mais chuvosos e superior nos meses de estiagem. $\mathrm{O}$ mesmo se manifesta em relação à Jaguaruana (Quadro 13). Esse elemento não parece trazer vantagem em termos de produtividade para nenhuma das regiões produtoras.

Quadro 13 - Nebulosidade (décimos) na CSB.

\begin{tabular}{|l|c|c|c|c|c|c|c|c|c|c|c|c|c|}
\hline MUNICÍPIOS & JAN & FEV & MAR & ABR & MAI & JUN & JUL & AGO & SET & OUT & NOV & DEZ & Ano \\
\hline Turiaçu - MA & 0,7 & 0,7 & 0,7 & 0,7 & 0.6 & 0.5 & 0.5 & 0,4 & 0,4 & 0,5 & 0,5 & 0,6 & 0,6 \\
\hline São Luís - MA & 0,7 & 0,8 & 0,8 & 0,8 & 0,7 & 0,6 & 0,5 & 0,5 & 0,5 & 0,5 & 0,5 & 0,6 & 0,6 \\
\hline Fortaleza - CE & 0,6 & 0,6 & 0,7 & 0,7 & 0,6 & 0,5 & 0,4 & 0,3 & 0,4 & 0,4 & 0,5 & 0,5 & 0,5 \\
\hline Jaguaruana - CE & 0,6 & 0,7 & 0,8 & 0,7 & 0,6 & 0,5 & 0,4 & 0,3 & 0,3 & 0,4 & 0,4 & 0,5 & 0,5 \\
\hline Macau - RN & 0,6 & 0,5 & 0,5 & 0,5 & 0,6 & 0,6 & 0,5 & 0,5 & 0,5 & 0,5 & 0,5 & 0,5 & 0,5 \\
\hline
\end{tabular}

Fonte: Normais Climatológicas do Brasil 1961-1990.

\subsection{Da umidade relativa do ar}

A umidade relativa do ar é outro parâmetro importante para o estado dos condicionantes climáticos da produção de sal marinho, isso porque ela influencia diretamente no processo de evaporação. Quanto mais seco o ar, maiores as taxas de evaporação.

Em termos de umidade relativa do ar compensada, não há surpresas na CSB, já que nos locais onde se tem as maiores taxas de precipitação média anual, ou seja, mais a noroeste, são registradas as maiores médias de umidade relativa do ar (Quadro 14). Macau por ser a estação litorânea que registra as menores taxas de precipitação pluviométrica, tem também as menores taxas de umidade relativa do ar. Excetuando-se o mês de setembro, Macau tem as menores taxas de umidade relativa do ar em todos os meses do ano, entre todas as estações meteorológicas da CSB. Isso vem a ser uma grande vantagem em termos de produtividade para o sal marinho para o LSP. As taxas médias tendem a aumentar, à medida que se aproxima de São Luís. A umidade relativa do ar compensada em Fortaleza chega a ser superior à do clima úmido de Natal.

Quadro 14 - Umidade relativa do ar compensada (\%) em estações selecionadas.

\begin{tabular}{|c|c|c|c|c|c|c|c|c|c|c|c|c|c|}
\hline Estações & JAN & FEV & MAR & ABR & MAI & JUN & JUL & AGO & SET & OUT & NOV & DEZ & Ano \\
\hline São Luí & 85 & 88 & 89 & 90 & 89 & 86 & 86 & 84 & 81 & 81 & 79 & 81 & 84,9 \\
\hline Fortaleza - CE & 78,1 & 81,4 & 84,7 & 85,2 & 83,6 & 81,0 & 78,8 & 75,3 & 74,4 & 74,0 & 73,7 & 75,9 & 78,8 \\
\hline Jaguaruana - CE & 71 & 75 & 82 & 82 & 79 & 77 & 74 & 68 & 68 & 67 & 68 & 69 & 73,3 \\
\hline Macau - RN & 70,0 & 72,0 & 75,0 & 76,0 & 76,0 & 70,0 & 69,0 & 69,0 & 68,0 & 69,0 & 66,0 & 70,0 & 70,8 \\
\hline Natal - RN & 74,8 & 75,1 & 77,3 & 79,9 & 80,1 & 81,3 & 80,5 & 78,0 & 75,5 & 74,4 & 75,4 & 74,8 & 77,3 \\
\hline
\end{tabular}

Fonte: Normais Climatológicas do Brasil 1961-1990. 
A umidade relativa do ar tende a ser maior no continente à noite, pois nesse período, a ascensão de ar carregando umidade praticamente cessa. O mais comum é que no período da tarde, quando a terra está mais aquecida, se tenha as menores taxas de umidade relativa do ar, inclusive em relação ao período da manhã quando a terra ainda não está aquecida.

Os quadros 15, 16 e 17 mostram que o acima exposto é comum à maioria das estações, pois registram maior umidade relativa do ar a noite ( $21 \mathrm{~h}$ local), diminuindo um pouco pela manhã ( $9 \mathrm{~h}$ local) para registrar os menores valores a tarde (15h local). Isto ocorre em quase todo o ano em São Luís, Fortaleza e Jaguaruana (estações com dados disponíveis). A exceção mais uma vez é a área onde ocorre a maior parte das precipitações durante o dia, em Macau, em quase todo o ano a umidade é maior, à noite ( $21 \mathrm{~h}$ local), e tem os menores valores registrados pela manhã (9h local), com valores intermediários, à tarde (15h local). Atente-se para o fato de que o período matutino (9h local) é o de menores índices pluviométricos em Macau, mais um dado que confirma a tese de Kousky (1980).

Quadro 15 - Umidade relativa do ar horária (\%) média nos meses de janeiro a abril na CSB.

\begin{tabular}{|l|c|c|c|c|c|c|c|c|c|c|c|c|}
\hline \multirow{2}{*}{ Estações } & \multicolumn{3}{|c|}{ JANEIRO } & \multicolumn{3}{c|}{ FEVEREIRO } & \multicolumn{3}{c|}{ MARÇO } & \multicolumn{3}{c|}{ ABRIL } \\
\cline { 2 - 12 } & 1200 & 1800 & 2400 & 1200 & 1800 & 2400 & 1200 & 1800 & 2400 & 1200 & 1800 & 2400 \\
\hline São Luís - MA & 86,5 & 81,6 & 93,3 & 89,4 & 84,5 & 94,5 & 89,6 & 86,4 & 95,6 & 90,3 & 87,0 & 96,4 \\
\hline Fortaleza - CE & 82,9 & 77,3 & 88,2 & 86,5 & 80,2 & 89,8 & 89,1 & 82,7 & 92,1 & 88,8 & 83,0 & 93,3 \\
\hline Jaguaruana - CE & 70,9 & 64,2 & 86,5 & 77,2 & 70,5 & 90,4 & $*$ & $*$ & 91,8 & 81,9 & 76,4 & 94,4 \\
\hline Macau - RN & 73,3 & 77,4 & 80,6 & 75,8 & 78,8 & 81,7 & 78,8 & 80,3 & 83,9 & 80,1 & 80,2 & 85,3 \\
\hline
\end{tabular}

Fonte: Normais Climatológicas do Brasil 1961-1990.

Quadro 16 - Umidade relativa do ar horária (\%) média nos meses de maio a agosto na CSB.

\begin{tabular}{|l|c|c|c|c|c|c|c|c|c|c|c|c|}
\hline \multirow{2}{*}{ Estações } & \multicolumn{3}{|c|}{ MAIO } & \multicolumn{3}{c|}{ JUNHO } & \multicolumn{3}{c|}{ JULHO } & \multicolumn{3}{c|}{ AGOSTO } \\
\cline { 2 - 13 } & 1200 & 1800 & 2400 & 1200 & 1800 & 2400 & 1200 & 1800 & 2400 & 1200 & 1800 & 2400 \\
\hline São Luís - MA & 87,7 & 82,7 & 95,6 & 85,8 & 80,6 & 95,3 & 85,4 & 78,6 & 94,9 & 82,9 & 77,0 & 94,1 \\
\hline Fortaleza - CE & 87,3 & 80,5 & 92,5 & 84,6 & 77,5 & 91,0 & 82,0 & 76,4 & 90,3 & 78,1 & 74,1 & 87,9 \\
\hline Jaguaruana - CE & 78,2 & 70,2 & 93,4 & 76,4 & 68,4 & 91,9 & 74,3 & 65,6 & 90,2 & 69,1 & 58,7 & 87,2 \\
\hline Macau - RN & 78,0 & 78,0 & 84,0 & 77,9 & 75,0 & 84,8 & 76,0 & 74,3 & 83,1 & 72,2 & 72,5 & 81,2 \\
\hline
\end{tabular}

Fonte: Normais Climatológicas do Brasil 1961-1990.

Quadro 17 - Umidade relativa do ar horária (\%) média nos meses de setembro a dezembro e anual na CSB em UTC $(1200=8 \mathrm{~h}$ no local; $1800=15 \mathrm{~h}$ local; $2400=21 \mathrm{~h}$ local $) . *$ sem dados.

\begin{tabular}{|c|c|c|c|c|c|c|c|c|c|c|c|c|c|c|c|}
\hline \multirow[t]{2}{*}{ Estações } & \multicolumn{3}{|c|}{ SETEMBRO } & \multicolumn{3}{|c|}{ OUTUBRO } & \multicolumn{3}{|c|}{ NOVEMBRO } & \multicolumn{3}{|c|}{ DEZEMBRO } & \multicolumn{3}{|c|}{ ANO } \\
\hline & $\begin{array}{c}120 \\
0\end{array}$ & $\begin{array}{c}180 \\
0\end{array}$ & $\begin{array}{c}240 \\
0\end{array}$ & $\begin{array}{l}120 \\
0\end{array}$ & $\begin{array}{c}180 \\
0\end{array}$ & $\begin{array}{c}240 \\
0\end{array}$ & $\begin{array}{c}120 \\
0\end{array}$ & $\begin{array}{c}180 \\
0\end{array}$ & $\begin{array}{c}240 \\
0\end{array}$ & $\begin{array}{l}120 \\
0\end{array}$ & $\begin{array}{c}180 \\
0\end{array}$ & $\begin{array}{c}240 \\
0\end{array}$ & $\begin{array}{c}120 \\
0\end{array}$ & $\begin{array}{c}180 \\
0\end{array}$ & $\begin{array}{c}240 \\
0\end{array}$ \\
\hline São Luís - MA & 79,8 & 75,1 & 91,7 & 78,3 & 75,6 & 91,4 & 79,1 & 74,7 & 90,5 & 81,2 & 76,3 & 91,4 & 84,7 & 80,0 & 93,7 \\
\hline Fortaleza - CE & 77,4 & 74,5 & 86,6 & 77,2 & 74,8 & 86,3 & 76,6 & 74,5 & 86,3 & 79,1 & 75,5 & 87,7 & 82,5 & 77,6 & 89,3 \\
\hline $\begin{array}{l}\text { Jaguaruana - } \\
\text { CE }\end{array}$ & 65,6 & 59,1 & 83,5 & 66,4 & 62,5 & 84,2 & 66,6 & 62,3 & 84,0 & 68,3 & 62,0 & 85,0 & $*$ & $*$ & 88,5 \\
\hline Macau - RN & 69,8 & 75,5 & 80,0 & 70,6 & 76,8 & 81,0 & 71,4 & 76,9 & 81,9 & 71,9 & 77,1 & 80,9 & 74,7 & 76,9 & 82,4 \\
\hline
\end{tabular}

Fonte: Normais Climatológicas do Brasil 1961-1990. 


\subsection{Da evaporação}

A evaporação nada mais é que a passagem da água do estado líquido para o gasoso. Esse é um importante elemento do clima, pois é responsável pelo acréscimo de umidade ao ar e pelo resfriamento do ambiente, já que nesse processo:

[...] há um consumo de energia por parte das moléculas de água, na ordem de 600 calorias por grama, que fica nelas retido. Essa energia é chamada de calor latente de evaporação e é responsável por manter as moléculas de água no estado de excitação molecular pertinente aos gases, ou seja, ela é usada para manter a molécula de água como molécula de vapor (MENDONÇA ; DANNI-OLIVEIRA, 2007, p. 59).

O último elemento do clima analisado é o de maior importância em termos de potencial para a produção de sal marinho, pois quanto maior a taxa de evaporação, maior será a produtividade da indústria salineira, já que a água nos evaporadores ganhará salinidade mais rapidamente, tanto maior seja a razão de evaporação da água (velocidade de mudança do estado).

Ayoade (1996) pontua que caso exista umidade disponível na superfície onde ocorre a evaporação (isto é, superfície não limitante, com água o ano inteiro como corpos hídricos perenes), então a evaporação ocorrerá na razão máxima possível. Nesse caso, chamada de evaporação potencial. Ocorre na maior parte do ano nos tanques evaporadores das salinas nordestinas.

A razão de evaporação aumenta com o decréscimo da umidade relativa e o aumento da velocidade do vento, e eleva-se exponencialmente com o aumento da temperatura (MENDONÇA ; DANNI-OLIVEIRA, 2007, p. 60, grifos nossos).

Dado que as diferenças de temperatura no litoral em tela são ínfimas, os ventos têm papel mais importante, pois deslocam ar úmido de sobre a superfície onde ocorre a evaporação, substituindo-o por ar mais seco, o que mantém o processo de evaporação. Quanto mais velozes forem os ventos, maior será a taxa de renovação do ar. O grau de umidade do ar, por sua vez, também exerce influência sobre a evaporação, pois esse fator determina a capacidade do ar em conservar a umidade evaporada.

Considerando o exposto acima, a maior parte dos elementos climáticos contribui para que Macau tenha as maiores taxas de evaporação da CSB, pois lá os ventos são mais velozes, a umidade relativa do ar é um pouco menor e a temperatura média é levemente mais elevada (Quadro 18).

A Costa Branca tem as menores taxas de precipitação e uma predominância em receber ar seco do interior do continente. Essa região tem taxas de evaporação bastante elevadas, em torno dos $2000 \mathrm{~mm}$ anuais em Aracati/CE, Jaguaruana/CE e Mossoró/RN. Destaca-se novamente Macau, que além dos aspectos expostos acima, tem ventos muito velozes, que contribuem para taxas de 
evaporação superiores aos 2500 mm anuais, muito assemelhadas às dos desertos mais secos do mundo.

Quadro 18: Média da evaporação total (evaporímetro de piché), em mm, por mês e média por ano na CSB.

\begin{tabular}{|c|c|c|c|c|c|c|c|c|c|c|c|c|c|}
\hline Estações & JAN & FEV & MAR & ABR & MAI & JUN & JUL & AGO & SET & OUT & NOV & DEZ & Ano \\
\hline Turiaçu - MA & 84,6 & 56,6 & 53,3 & 44,9 & 52,1 & 58,5 & 69,1 & 89,2 & 118,3 & 130,8 & 130,4 & 119,5 & 1007,3 \\
\hline São Luís - MA & 78,8 & 52,7 & 53,8 & 46,7 & 55,0 & 67,8 & 77,4 & 94,6 & 116,1 & 126,4 & 130,4 & 111,7 & 1011,4 \\
\hline Parnaíba - PI & 150,0 & 91,1 & 82,7 & 73,0 & 85,6 & 105,6 & 144,1 & 192,2 & 208,0 & 227,1 & 223,7 & 207,0 & 1790,1 \\
\hline Acaraú - CE & 165,5 & 121,9 & 77,7 & 72,9 & 98,5 & 121,9 & 158,5 & 239,0 & 270,4 & 279,4 & 276,2 & 232,9 & 2114,8 \\
\hline Fortaleza - CE & 127,7 & 93,8 & 72,4 & 67,5 & 80,5 & 93,5 & 115,2 & 153,2 & 159,2 & 163,9 & 158,9 & 149,4 & 1435,2 \\
\hline Aracati - CE & 154,4 & 129,9 & 129,7 & 105,6 & 131,5 & 134,0 & 182,1 & 219,3 & 238,2 & 249,4 & 192,3 & 157,0 & 2023,4 \\
\hline Jaguaruana - CE & 195,3 & 137,1 & 104,6 & 90,9 & 105,4 & 124,7 & 167,4 & 204,9 & 225,0 & 231,3 & 214,4 & 206,2 & 2007,2 \\
\hline Mossoró-RN & 200,2 & 139,8 & 105,2 & 100,0 & 106,0 & 117,9 & 149,3 & 191,4 & 217,6 & 226,2 & 221,7 & 214,2 & 1989,5 \\
\hline Macau - RN & 216,9 & 191,6 & 176,3 & 164,0 & 189,2 & 196,5 & 214,1 & 269,5 & 263,7 & 258,3 & 235,5 & 215,8 & 2591,4 \\
\hline
\end{tabular}

Fonte: Normais Climatológicas do Brasil 1961-1990.

Mais uma vez para a geometria do litoral se manifesta de forma decisiva, pois na Costa das Dunas, que recebe majoritariamente ar úmido proveniente do Atlântico e onde mais chove, tem-se uma diminuição das taxas de evaporação para os 1435,2 mm médios em Fortaleza. Ao retomar a concavidade do litoral observa-se novamente o aumento na taxa média de evaporação para 2114,8 mm/ano em Acaraú e 1790,1 em Parnaíba.

Se forem levadas em consideração a diferença existente entre as taxas médias de precipitação e evaporação (Quadro 19), percebe-se que os dois trechos côncavos da CSB são os que se apresentam deficitários, novamente com larga vantagem para Macau que apresenta déficit de mais de $2000 \mathrm{~mm}$ por ano. A região de Mossoró tem também alto déficit com mais de 1200 mm/ano. Em Jaguaruana, o déficit é de mais de 1100 mm/ano. Outra área de considerável potencial para a produção de sal marinho é Acaraú com cerca de $570 \mathrm{~mm} /$ ano negativos, seguido do LP que também apresenta déficit em Parnaíba. Nas proximidades de Fortaleza há superávit, sendo que a Costa das Dunas é a pior área para a produção de sal marinho em termos de potencial produtivo em relação ao clima.

Quadro 19: Precipitação média compensada, evaporação média compensada e déficit entre precipitação e evaporação em mm na CSB.

\begin{tabular}{|l|c|c|c|c|}
\hline MUNICÍPIOS & Prec. & Evap. & Prec.- Evap.(mm) & Meses com déficit \\
\hline Turiaçu - MA & 2222,0 & 1007,3 & 1221,7 & 5 \\
\hline São Luís - MA & 2290,0 & 1011,4 & 1278,6 & 5 \\
\hline Parnaíba - PI & 1596,4 & 1790,1 & $-193,7$ & 8 \\
\hline Acaraú - CE & 1545,2 & 2114,8 & $-569,6$ & 8 \\
\hline Fortaleza - CE & 1609,4 & 1435,2 & 174,2 & 7 \\
\hline Jaguaruana - CE & 862,0 & 2007,2 & $-1145,2$ & 9 \\
\hline Mossoró-RN & 787,9 & 1989,5 & $-1201,6$ & 12 \\
\hline Macau - RN & 507,2 & 2591,4 & $-2084,2$ & 9 \\
\hline
\end{tabular}

Fonte: Normais Climatológicas do Brasil 1961-1990 
Caso se feita esta comparação mês a mês (quadros 1, 18 e 19), as altíssimas taxas de evaporação fazem com que a região de Macau apresente déficit em todos os meses do ano em termos médios. No geral, esse déficit também é mais longo em outras áreas da Costa Branca, pois Jaguaruana e Mossoró têm 9 meses de déficit. Na Costa dos Deltas o déficit também é longo e se estende por 8 meses em Acaraú e Parnaíba, e é menor na Costa das Dunas. Fortaleza tem em média 7 meses de déficit para este parâmetro.

\section{CONCLUSÕES}

Do ponto de vista climático, os dois trechos côncavos da CSB são os de maior potencial para a produção de sal marinho em termos de Brasil, pois neles é menor a taxa de precipitação e a umidade relativa do ar, sendo maior a velocidade dos ventos e a temperatura, o que concorre para serem maiores também as taxas de evaporação da água. A situação é tanto mais favorável na Costa Branca, especialmente no LSP, e de forma ainda mais marcante na região de Macau, onde todos os principais indicadores apontam para um maior potencial para a produção de sal marinho dessa área.

Os efeitos da maritimidade não se fazem sentir em ganhos de umidade (relativa do ar ou de precipitação pluviométrica) na Costa Branca. Em relação às áreas mais interioranas adjacentes, em especial na região de Macau, os ventos predominantes de sudeste concorrem muito mais para trazer ar seco do interior para o litoral do que para a chegada de umidade proveniente do oceano.

No início deste artigo esta escrito "estes elementos (do clima) são controlados por fatores climáticos como latitude, altitude, maritimidade, massas de ar e rugosidade do relevo", porém, acrescente-se que para o estudo do clima litorâneo a geometria do litoral (da linha de costa) é um fator geográfico de grande relevância, sendo que para a CSB esse é o fator de maior relevância e determinante para a instalação da atividade salineira.

\section{REFERÊNCIAS}

AYOADE, J. O. Introdução à climatologia dos trópicos. 4. Ed. Rio de Janeiro: Bertrand Brasil, 1996.

DINIZ, M. T. M.; OLIVEIRA, G. P. PROPOSTA DE COMPARTIMENTAÇÃO EM MESOESCALA PARA O LITORAL DO NORDESTE BRASILEIRO. Revista Brasileira de Geomorfologia, v. 17, p. 565-590, 2016.

DINIZ, M. T. M.; VASCONCELOS, F. P.; OLIVEIRA, G. P. ; BERNARDINO, D. B. S. M. . Geografia Costeira do Nordeste: bases naturais e tipos de uso. 1. ed. Curitiba: CRV, 2016. v. 1. $135 \mathrm{p}$. 
GAUSSEN, Henri; BAGNOULS, F., Saison sèche et indice xérothermique, Université de Toulouse, Faculté des Sciences, 1953.

INMET. Instituto Nacional de Meteorologia. Normais Climatológicas do Brasil 1961-1990. Organizadores: Andrea Malheiros Ramos, Luiz André Rodrigues dos Santos, Lauro Tadeu Guimarães Fortes. Brasília, DF: INMET, 2009.

KOUSKY, V. E. Diurnall rainfall variation in the Northeast Brazil. Monthly Weather Review, Boston, v.108, n.4, p. 488 - 498. 1980.

MACHADO, L. A. T.; FERREIRA, N. J.; LAURENT, H.; DIEDHIOU, A. Distúrbios ondulatórios de leste. In: Cavalcanti, I. F. A. et al (org.). Tempo e Clima no Brasil. São Paulo: Oficina de Texto, 2009.

MELO, A. B. C.; CAVALCANTI, I. F de A.; SOUZA, P. P. Zona de Convergência Intertropical do Atlântico. In: Cavalcanti, I. F. A. et al (org.). Tempo e Clima no Brasil. São Paulo: Oficina de Texto, 2009.

MENDONÇA, F.; DANNI-OLIVEIRA, I. M. Climatologia: noções básicas e climas do Brasil. São Paulo: Oficina de Textos, 2007.

MOLION, L. C. B.; BERNARDO, S. O. Uma revisão da dinâmica das chuvas no nordeste brasileiro. Revista Brasileira de Meteorologia, Rio de Janeiro, v. 17, n. 1, p. 1-10, 2002.

SUDENE. Superintendência do Desenvolvimento do Nordeste. Dados pluviométricos mensais do Nordeste. Superintendência do Desenvolvimento do Nordeste, Recife, 1990 (Série Pluviometria 1 a $10)$.

TEIXEIRA, R. F. B. O fenômeno da brisa e sua relação com a chuva sobre Fortaleza-CE. Revista Brasileira de Meteorologia, v.23, n.3, 2008.

WALTER, H.; LIETH, H. Klimadiagram. In: Weltatlas, Jenna, Veb. Gustv. Fischer Verlaf, 1960. 